\title{
Biodegradable, metal-chelating compounds as alternatives to EDTA for cultivation of marine microalgae
}

\author{
Justine Sauvage ${ }^{1} \cdot$ Gary H. Wikfors $^{2} \cdot$ Koen Sabbe $^{3} \cdot$ Nancy Nevejan $^{4} \cdot$ Steven Goderis ${ }^{5} \cdot$ Philippe Claeys $^{5} \cdot$ Xiaoxu Li $^{6}$. \\ Alyssa Joyce ${ }^{1}$
}

Received: 24 March 2021 / Revised and accepted: 28 July 2021 / Published online: 16 September 2021

(c) The Author(s) 2021

\begin{abstract}
Iron $(\mathrm{Fe})$ is an essential nutrient for microalgal metabolism. The low solubility of $\mathrm{Fe}$ in oxic aquatic environments can be a growth-limiting factor for phytoplankton. Synthetic chelating agents, such as ethylenediaminetetraacetic acid (EDTA), are used widely to maintain Fe in solution for microalgal cultivation. The non-biodegradable nature of EDTA, combined with sub-optimal bioavailability of Fe-EDTA complexes to microalgae, indicates opportunity to improve microalgal cultivation practices that amplify production efficiency and environmental compatibility. In the present study, the effects of four organic chelating ligands known to form readily bioavailable organic complexes with $\mathrm{Fe}$ in natural aquatic environments were investigated in relation to growth and biochemical composition of two marine microalgae grown as live feeds in shellfish hatcheries (Chaetoceros calcitrans and Tisochrysis lutea). Three saccharides, alginic acid (ALG), glucuronic acid (GLU), and dextran (DEX), as well as the siderophore desferrioxamine B (DFB), were compared to EDTA. Organic ligands characterized by weaker binding capacity for cationic metals (i.e., ALG, GLU, DEX) significantly improved microalgal growth and yields in laboratory-scale static batch cultures or bubbled photobioreactors. Maximal microalgal growth enhancement relative to the control (e.g., EDTA) was recorded for GLU, followed by ALG, with 20-35\% increase in specific growth rate in the early stages of culture development of C. calcitrans and T. lutea. Substitution of EDTA with GLU resulted in a 27\% increase in cellular omega 3-polyunsaturetd fatty acid content of $C$. calcitrans and doubled final cell yields. Enhanced microalgal culture performance is likely associated with increased intracellular Fe uptake efficiency combined with heterotrophic growth stimulated by the organic ligands. Based upon these results, we propose that replacement of EDTA with one of these organic metal-chelating ligands is an effective and easily implementable strategy to enhance the environmental compatibility of microalgal cultivation practices while also maximizing algal growth and enhancing the nutritional quality of marine microalgal species commonly cultured for live-feed applications in aquaculture.
\end{abstract}

Keywords Microalgae production · Extracellular polymeric substance (EPS) · Iron bioavailability · Organic chelating ligands $\cdot$ Live aquaculture feed

Alyssa Joyce

alyssa.joyce@gu.se

1 Department of Marine Sciences, University of Gothenburg, Carl Skottbergsgata 22 B, 41319 Göteborg, Sweden

2 NOAA Fisheries Service (NMFS) Northeast Fisheries Science Center, Milford, CT 06460, USA

3 Laboratory of Protistology \& Aquatic Ecology, Department of Biology, Ghent University, Ghent, Belgium
4 Laboratory of Aquaculture \& Artemia Reference Center, Faculty of Bioscience Engineering, Ghent University, Ghent, Belgium

5 Analytical, Environmental and Geo-Chemistry, Vrije Universiteit Brussel, Brussels, Belgium

6 South Australian Research and Development Institute, Primary Industries and Regions (PIRSA) Aquatic Sciences Centre, West Beach, South Australia, Australia 


\section{Introduction}

Microalgal biomass and derived products are biological resources relevant to various products in the feed, food, energy, and pharmaceutical sectors (Vanthoor-Koopmans et al. 2013; Enzing et al. 2014; Koller et al. 2014). Microalgal growth in the natural environment, as well as in controlled cultivation systems, occurs within a complex suite of environmental parameters including light, nutrients, temperature, $\mathrm{pH}$, and salinity (Lavens and Sorgeloos 1996). Iron (Fe) nutrition is essential for phytoplankton metabolism. This nutrient is required for numerous biological processes (e.g., photosynthesis and respiration, chlorophyll synthesis, and detoxification of reactive oxygen species) (Sunda and Huntsman 1995a; Marchetti and Maldonado 2016) that significantly affect algal productivity and biomass composition (Liu et al. 2008). The most readily available form of Fe to phytoplankton, the oxidized ferric form of inorganic $\mathrm{Fe}(\mathrm{Fe}(\mathrm{III}))$, is poorly soluble in oxygenated waters and rapidly precipitates into biologically unavailable complexes (i.e., hydrous ferric oxides) (Byrne and Kester 1976; Anderson and Morel 1982; Johnson et al. 1997; Turner and Hunter 2001).

To compensate for low Fe bioavailability (defined here as the degree to which a Fe-substrate can be accessed and utilized by an organism), a plethora of inorganic and organic processes have evolved to enable phytoplankton to meet $\mathrm{Fe}$ requirements in oxic aquatic environments where dissolved "free" (unchelated) Fe can be growth-limiting (Morel et al. 2008; Shaked and Lis 2012). The processes and factors governing $\mathrm{Fe}$ bioavailability are multifaceted, with aspects of Fe speciation and kinetics, phytoplankton physiology, light, temperature, and microbial interactions all intricately intertwined (Bruland et al. 1991; Sunda and Huntsman 1995b; Worms et al. 2006; Shaked and Lis 2012). Although our understanding of this complex ecological interplay remains partial (Shaked and Lis 2012), advances in aquatic Fe biogeochemistry and microbial ecology (Hassler et al. 2011, 2015; Norman et al. 2015) have revealed opportunities for direct applications to the optimization of microalgal cultivation. In the marine environment, most dissolved $\mathrm{Fe}(\mathrm{III})$ is bound to naturally occurring organic compounds, which increases solubility and residence time in solution, and is thus a determining factor for phytoplankton growth (Rue and Bruland 1995; Gledhill and Buck 2012). In addition, complex feedbacks exist between microorganisms and $\mathrm{Fe}$ wherein biologically produced, Fe-chelating molecules (e.g. exopolymeric substances and siderophores) can influence Fe chemistry with consequences for bioavailability (Völker and Wolf-Gladrow 1999; Shaked and Lis 2012; Hassler et al. 2015).

Most microorganisms, including microalgae and bacteria, release organic compounds, which are often grouped under the term extracellular polymeric substances (EPS), as part of fundamental metabolism (Decho and Gutierrez 2017). EPS possess a wide range of chemical structures and are composed of a variety of macromolecules (e.g., amino acids, saccharides, proteins, and carbohydrates) containing polyanionic (negatively charged) functional groups (e.g., carboxylic, phosphoric, and uronic acid groups) with high metallic-cation-binding properties (Kennedy and Sutherland 1987; Aluwihare et al. 1997; Liu and Fang 2002; Decho and Gutierrez 2017). In natural aquatic environments, a major pool of EPS serves as precursor for the formation of transparent exopolymer particles (TEPs), which are large $(<1$ to $200 \mu \mathrm{m}$ in longest dimension), discrete, suspended microgels rich in saccharides, and operationally defined as being retained by a filter with a pore size of $>0.4 \mu \mathrm{m}$ (Alldredge et al. 1993; Decho and Gutierrez 2017). Although the biochemical properties of marine bacterial and microalgal EPS and TEP, and their contribution to $\mathrm{Fe}$ biogeochemistry (e.g., the nature of their Fe-binding properties and how these relate to Fe solubility and bioavailability) remain poorly defined, the paramount importance of organic complexation for determining Fe bioavailability and phytoplankton growth in aquatic environments is well-established (Flemming and Wingender 2001; Hassler et al. 2011, 2017; Gutierrez et al. 2012).

Industrial microalgal bioreactors are characterized by continuous light and excess nutrient availability (Muller-Feuga 2013). To support optimal microalgae growth, seawater-based culture medium formulations are enriched with dissolved, essential metals (including $\mathrm{Mn}, \mathrm{Fe}, \mathrm{Co}, \mathrm{Ni}, \mathrm{Cu}$ and $\mathrm{Zn}$ ), in balanced proportions, at concentrations that are neither limiting nor toxic (Guillard and Ryther 1962; Anderson and Morel 1982; Bruland et al. 1991). Depending upon the culture system and the intended use of the cultured algae, a variety of mechanical and/or chemical water treatment procedures are undertaken to condition the growth media prior to microalgal inoculation. In the case of bivalve hatcheries, for example, filtration and/ or high temperature and pressure treatment (autoclaving or pasteurization) of seawater results in low bacterial levels within the growth medium (Richmond 2008). Water sterilization eliminates nutrient competition between bacteria and algae and also reduces the risk of introducing pathogenic bacteria into larval cultures feeding on cultured microalgae (Nicolas et al. 2004). As a result, microorganisms that would normally release metal-complexing agents in situ are removed, and in the process, the suite of naturally occurring organic compounds in seawater which act as metal-chelating agents is diminished (Richmond 2008; Joyce and Utting 2015). Consequently, poor Fe solubility, restricted bioavailability, and resulting microalgal Fe-deficiency may be recurring growth-limiting factors in commercial microalgal cultivation systems (Liu et al. 2008; Joyce and Utting 2015). Natural (e.g., humic compounds) and synthetic (e.g., aminopolycarboxylate chelating agents, such 
as ethylenediaminetetraacetic acid (EDTA) and nitrilotriacetic acid (NTA)) metal-chelating agents, first repurposed from agricultural soil amendment products in the 1950s, are now included in most freshwater and marine microalgal culture growth media to provide a constant and controlled supply of free metal ions (Hutner et al. 1950; Myers et al. 1951; Anderson and Morel 1982; Gerringa et al. 2000). Despite widespread use and utility in diverse industrial processes, synthetic metal chelators such as EDTA have a number of detrimental environmental consequences arising from intrinsically poor biodegradability and their potential to promote the remobilization and bioavailability of heavy metal pollutants in the environment upon discharge (Oviedo and Rodríguez 2003; Pinto et al. 2014). To mitigate the ecotoxicological risks associated with the use of EDTA in microalgal cultivation, the evaluation of biodegradable alternatives that can still support optimal microalgal growth performance is a priority for sustainable aquaculture and bio-based industries.

Recent field and laboratory studies have generated compelling evidence for the pivotal role of EPS components (e.g., saccharides and uronic acids) in enhancing Fe solubility, and most importantly Fe bioavailability and microalgal Fe uptake in both natural and cultured marine microalgal populations (Rue and Bruland 2001; Hassler and Schoemann 2009; Hassler et al. 2011, 2015). Hassler and co-workers (Hassler et al. 2015) have demonstrated that Fe bound to algal EPS is not only highly bioavailable but is also extremely efficient at sustaining the growth and photosynthetic efficiency in the diatom Chaetoceros simplex under laboratory conditions. Increased Fe bioavailability in the presence of saccharides is attributed to both the formation of bioavailable (or chemically labile) organic forms of $\mathrm{Fe}$ and the stabilization of Fe within the dissolved phase (mainly as colloidal Fe) (Hassler and Schoemann 2009; Benner 2011). Substitution of EDTA with biodegradable chelating ligands (e.g., hydroxyiminodisuccinic acid (HIDS), methylglycinediacetic acid, and iminodisuccinate) in the growth medium resulted in higher intracellular Fe concentrations in three coastal phytoplankton species (Hasegawa et al. 2018). Similarly, in hydroponic systems, substitution of EDTA with HIDS, when used in the cultivation of rice seedlings (Oryza sativa $L$ ), resulted in optimized Fe cycling (enhanced Fe solubility and more efficient $\mathrm{Fe}$ uptake) and faster plant growth (Rahman et al. 2009; Hasegawa et al. 2012). Collectively, such evidence highlights the sub-optimal growth conditions in EDTA-chelated culture media (Hasegawa et al. 2018).

Although our knowledge of trace metal organic complexation and its relationship to $\mathrm{Fe}$ bioavailability and assimilation in both marine and terrestrial environments has progressed substantially (Worms et al. 2006; Gledhill and Buck 2012; Hassler et al. 2015), these advances have not directly transitioned into practical solutions for the optimization of microalgal cultivation. To encourage this transition, in the present study, we examined the efficacy of organic metal-chelating ligands as EDTA alternatives in microalgal growth media and assessed performance of two key marine microalgal species (Chaetoceros calcitrans and Tisochrysis lutea) used for the production of live aquaculture feeds (Guedes and Malcata 2012; Brown and Blackburn 2013). As Fe bioavailability and Fe uptake strategies depend upon both cell size and microalgal species, two microalgal species with distinct cell morphology and taxonomy (haptophyte vs. centric diatom) were selected as model organisms for this study. Four organic ligands with varying physicochemical properties and chelating strengths, and representing chemical analogues of marine compounds within the pool of organic ligands enhancing iron bioavailability, were evaluated in this study: (i) the polysaccharide alginic acid extracted from brown macroalgae, (ii) the siderophore desferrioxamine B, (iii) the monosaccharide glucuronic acid, and (iv) the bacterially secreted polysaccharide Dextran (Hassler et al. 2011). The effect of EDTA substitution with organic ligands upon microalgal growth rate, algal biomass composition (C:N ratio, unsaturated fatty acid content and chlorophyll $a$ ), algal EPS production, and Fe solubility was determined. Treatment effects were evaluated relative to the results obtained in standard (EDTAchelated) growth media. These experimental, alternative ligand culture media additives were tested at different concentrations under both laboratory (static batch cultures) and small-scale bubbled bioreactor settings that are characteristic of the microalgal cultivation systems found in bivalve hatcheries for live algal feed production (Brown and Blackburn 2013).

\section{Materials and methods}

\section{Marine microalgae}

For laboratory-scale experiments, bacteria-free Tisochrysis lutea (T-Iso) and Chaetoceros calcitrans (Chaet cal.) cultures were obtained from the NOAA Milford Laboratory Microalgal Culture Collection, Northeast Fisheries Science Center, Milford, CT, USA. The marine flagellate T. lutea, a species within the haptophyte clade, is one of the most commonly cultured microalgae used as a live feed in aquaculture because of its rapid growth rate and high docosahexaenoic acid (DHA) content (Bendif et al. 2013). The diatom $C$. calcitrans is routinely produced in mass cultures (Kaspar et al. 2014) and represents a key shellfish hatchery species because of its small size and nutritional profile containing essential polyunsaturated fatty acids (Tredici et al. 2009) as well as metabolizable sterols (Tsitsa-Tzardis et al. 1993).

For shellfish hatchery trials at the Australian Research and Development Institute (SARDI-PIRSA), bacteriafree microalgal strains (Chaetoceros calcitrans (CS-178) and Tisochrysis lutea (CS-177)) were sourced from the 
Australian National Algae Culture Collection, CSIRO, Hobart, Australia.

Prior to the onset of the microalgal culture experiments, starter cultures were maintained in 500-mL Erlenmeyer flasks containing $1-\mu \mathrm{m}$-filtered, autoclave-sterilized, Guillard's F (full strength) nutrient-enriched seawater (Guillard and Ryther 1962). Starter cultures were kept at $19{ }^{\circ} \mathrm{C}$, exposed continuously to cool-white fluorescent light, and swirled gently daily.

\section{Experimental solutions and metal-chelating ligands}

The experimental growth media in the Milford Laboratory experiment consisted of 1- $\mu \mathrm{m}$-filtered Milford Harbor seawater (salinity 26, pH 7.9) enriched with "modified" F-nutrients, wherein EDTA was substituted with one of the candidate, alternative metal-chelating agent (Guillard and Ryther 1962; Guillard 1975). The adapted F-nutrient growth media were selected to match microalgal growth conditions commonly found in commercial shellfish hatcheries (Helm 2004).

Following the F-nutrients seawater growth medium formulation, iron chloride hexahydrate $\left(\mathrm{FeCl}_{3} \cdot 6 \mathrm{H}_{2} \mathrm{O}\right.$; special grade, Mallinkrodt), dosed at $0.23 \mu \mathrm{M}$, was used for the experimental media preparation (Guillard and Ryther 1962; Guillard 1975). The organic ligands examined in this study were selected to represent the groups of hydroxamate siderophores (desferrioxamine B (DFB)) and saccharides (monosaccharide D-glucuronic acid (GLU); and polysaccharides alginic acid (ALG) and dextran (DEX)). Powders of (i) D-glucuronic acid ( $>98 \%$ purity), (ii) alginic acid extracted from the brown macroalgae Macrocystis pyrifera, (iii) dextran, a bacterial extracellular polysaccharide from Leuconostoc spp., and (iv) desferrioxamine B were sourced from Sigma-Aldrich.

Microalgal growth and other responses to experimental treatments were evaluated relative to a control consisting of standard Guillard's F-nutrient-enriched seawater, with EDTA (Sigma-Aldrich) as metal chelator. Stock solutions of EDTA and organic ligands of $1 \mathrm{mM}$ were prepared with $0.25-\mu \mathrm{m}$-filtered, ultra-pure water (Millipore Element, 18.2 $\mathrm{M} \Omega \mathrm{cm}$ ). To avoid modification or destruction of the metalchelating agents, the experimental growth media were autoclave-sterilized before these were added.

Each EDTA and organic ligand experimental medium additive was added as a single dose to obtain a final culture concentration of $0.23 \mu \mathrm{M}$, consistent with Guillard's F-nutrients growth media formulation for metal-chelating agent dosage. As a negative control, a treatment consisting of F-nutrient-enriched seawater with omission of EDTA (referred as No EDTA treatment) was added. To study dosage effects, $\mathrm{Fe}$ and organic ligand concentrations in the experimental media were amplified by a factor 5 and 10 , respectively, equivalent to $1.15 \mu \mathrm{M}$ and $2.34 \mu \mathrm{M}$ final culture concentration. Following addition of the organic metal-chelating ligands, the experimental media were left to equilibrate overnight prior to microalgal culture inoculation. Assuming equilibration within $24 \mathrm{~h}$, the Fe-reactive organic ligands were likely bound and saturated with $\mathrm{Fe}$ (Hassler and Schoemann 2009) and as such, alternative ligand culture media additive treatments corresponded to organically bound Fe speciation treatments.

Prior to inoculation, growth media aliquots $(2 \mathrm{~mL} \times 2)$ were sampled for dissolved Fe concentration and TEP abundance analysis. Samples were taken in triplicate. Aliquots for dissolved $\mathrm{Fe}$ concentration measurements were stored in acid-washed centrifuge vials. Acid cleaning procedures as outlined in Cullen and Sherrell (1999) were applied. To avoid Fe precipitation onto the centrifuge vials during sample storage, $0.01 \mu \mathrm{L} \mathrm{70 \%} \mathrm{trace} \mathrm{metal} \mathrm{grade} \mathrm{HNO}_{3}$ (SigmaAldrich) was added to the samples.

\section{Microalgal growth experiments comparing different metal-chelating ligands}

Static batch-culture experiments were conducted at the NOAA Milford Laboratories in Milford, CT, USA. Fernbach flasks (2.8-L) were filled with $650 \mathrm{~mL}$ modified F-enriched seawater media and inoculated with $70 \mathrm{~mL}$ microalgal starter culture. Initial cell densities for $C$. calcitrans and T. lutea cultures were $1.00-1.15 \times 10^{6}$ cells $\mathrm{mL}^{-1}$. All cultures were kept at a constant temperature $\left(19 \pm 0.5^{\circ} \mathrm{C}\right)$ under continuous illumination. The artificial light source consisted of $1.2-\mathrm{m}$ fluorescent light tubes (T8 35 Watt, $4100 \mathrm{~K}$, GE Ecolux with Starcoat, F32T8 SPP4) located $30 \mathrm{~cm}$ from the culture flasks illuminating one side of the cultures at a photosynthetically active radiation (PAR) light intensity of $\sim 120 \mu$ mol photons $\mathrm{m}^{-2} \mathrm{~s}^{-1}$, measured at the surface of the flasks with a Licor Inc., Quantum/Radiometer/Photometer (Model LI-185B). Experimental flasks were capped with a cotton stopper, randomly organized, and swirled daily to remobilize cells and promote gas exchange. Experimental treatments were conducted in quadruplicate (4 biological replicates per treatment, $n=4)$. Experimental cultures were incubated under conditions detailed above until maximal population yields of $C$. calcitrans and T. lutea were reached (i.e., 21 and 15 days, respectively). Culture aliquots were withdrawn aseptically every 2 days, during early stages of culture development, and every 3 days when approaching the stationary growth phase for microalgal cell density determination using an Accuri C6 + flow cytometer (BD Biosciences, USA).

During the course of the experiment, aseptic techniques were employed to prevent bacterial contamination in all culture manipulation and solution preparations. Following termination of the experiment, the absence of bacteria in the 
cultures was confirmed utilizing SYTO 9 (ThermoFisher) staining of culture aliquots that specifically binds to bacterial DNA. Stained bacterial cells were detected using flow cytometry. Algal cultures were considered bacteria-free if counts within the bacterial gate were below 100 flow cytometer events per $\mathrm{mL}$ of sample analyzed (at this level considered to be electronic noise events).

\section{Photobioreactor microalgal growth experiments, description, and experimental design}

Experimental organic ligand treatments that were carried out for static batch cultures at the NOAA Milford Laboratories were repeated in small, hatchery-style bioreactors to ensure replicability at the SARDI-PIRSA site. Photobioreactors were accommodated with an influx of an air/ $/ \mathrm{CO}_{2}$ mixture designed to mimic medium-scale microalgae production units commonly found in shellfish hatcheries (carboy or bag cultivation) (Helm 2004). Photobioreactors consisted of 250-mL Erlenmeyer flasks, each fitted with a rubber stopper with two holes serving as the gas inlet and outlet. Air at a flow rate of $0.4 \mathrm{~L} \mathrm{~min}{ }^{-1}$ with $0.5 \% \mathrm{CO}_{2}$ /air mixture was sparged from the bottom of the flask by a glass distribution tube that was inserted into the photobioreactor through one of the holes in the cap. LED lamps were used to illuminate the photobioreactors from one side of the flasks with a continuous PAR light intensity of $130 \mu \mathrm{mol}$ photons $\mathrm{m}^{-2} \mathrm{~s}^{-1}$ measured at the surface of the flasks. The total culture volume in each reactor was $150 \mathrm{~mL}$, consisting of autoclave-sterilized, modified F-enriched seawater medium (30 ppt, $\mathrm{pH} 8$ ) and algal inoculum $(20 \mathrm{~mL})$. Evaluated treatments in the photobioreactor experimental setting were performed in triplicate. Initial cell counts ranged between 1 and $1.310^{5}$ cells $\mathrm{mL}^{-1}$ for $C$. calcitrans and T. lutea. The temperature of the reactors was maintained at $20.5{ }^{\circ} \mathrm{C}$. The $\mathrm{CO}_{2}$ /air mixture ratio was increased gradually during algal culture development to maintain the desired culture $\mathrm{pH}$ of 8.2. Bubbled photobioreactor microalgal growth experiments for each treatment were conducted in triplicate $(n=3)$. Microalgal culture development was monitored every 2 days throughout the course of the experiment by aseptically extracting a $200 \mu \mathrm{L}$ culture subsample followed by the enumeration of microalgal cells by flow cytometry (Accuri C6 + flow cytometer). Experiments were terminated after confirmation that the cultures had reached stationary phase for two consecutive sampling points ( $\sim$ days). Algal culture growth condition variables (temperature, light, $\mathrm{CO}_{2}$ flow, and $\mathrm{pH}$ ) were monitored periodically throughout the course of the experiment. Prior to termination of the algal growth experiments, the absence of bacteria in the microalgal cultures was confirmed utilizing SYTO 9 staining of culture aliquots followed by flow cytometry enumeration of stained particles. At the onset of the stationary phase (i.e., after 8 days culture period), a $100-\mathrm{mL}$ culture subsample was collected to quantify microalgal culture transparent exopolymer particle (TEP) concentration, chlorophyll $a$ concentration, and for algal biomass biochemical composition characterization.

\section{Biochemical analysis}

For each treatment and replicate culture $(n=3)$, microalgae harvested at the start of the stationary phase were used for quantification of algal biomass $\mathrm{C}: \mathrm{N}$ ratio, fatty acid composition and concentration, and chlorophyll $a$ concentration. Microalgal culture samples were centrifuged at $7000 \times g$ at $15{ }^{\circ} \mathrm{C}$ for $15 \mathrm{~min}$ to obtain concentrated algal pellets which were freeze-dried prior to analysis. Fatty acid methyl esters (FAMEs) were extracted using a modification of the Lepage and Roy (1984) protocol based upon a methanol/toluene $(3: 2 \mathrm{v} / \mathrm{v})$ combined with acetylchloride/ methanol $(1: 20 \mathrm{v} / \mathrm{v})$ extraction method as described in Sauvage et al. (2021). FAMEs were separated and measured by gas chromatography using an Agilent 7890B Gas Chromatograph equipped with a polar capillary column, BPX70 (Forte series, SGE Australia, 50 m, 0.32-mm internal diameter, $0.25-\mu \mathrm{m}$ film thickness). For each analysis, a 20 $\mu \mathrm{L}$ subsample of lipid extract diluted in iso-octane was injected into the instrument. Hydrogen was the carrier gas

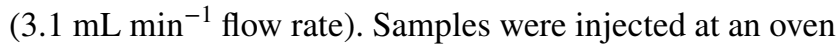
temperature of $85^{\circ} \mathrm{C}$, which was increased to $150^{\circ} \mathrm{C}$ at a rate of $30^{\circ} \mathrm{C} \mathrm{min}^{-1}$. The temperature conditions were further adjusted past $150{ }^{\circ} \mathrm{C}$ : increase at $0.1{ }^{\circ} \mathrm{C} \mathrm{min}^{-1}$ from 150 to $152{ }^{\circ} \mathrm{C}$, at $0.5^{\circ} \mathrm{C} \mathrm{min}^{-1}$ from 152 to $172{ }^{\circ} \mathrm{C}$, at $50{ }^{\circ} \mathrm{C} \mathrm{min}^{-1}$ from 172 to $200{ }^{\circ} \mathrm{C}$ and then held for $7 \mathrm{~min}$. Standard reference FAME mixtures (GLC-68 series, Nu-Chek-Prep, Inc., USA) were used for FAME peak identification on the chromatograms. Individual FAME concentrations in each sample were quantified relative to the concentration of the internal standard.

Total carbon and nitrogen contents of microalgal biomass, expressed as a percent of dry mass, were quantified by combustion at $1025{ }^{\circ} \mathrm{C}$ using an elemental analyzer (Flash 200 Elemental Analyzer, Thermo Scientific). Helium was used as a carrier gas and sulfanilamide was used for instrument calibration.

Chlorophyll $a(\mathrm{Chl} a$ ) analysis followed Li et al. (2009). Briefly, microalgae culture samples $(0.5 \mathrm{~mL})$ were filtered onto $0.7-\mu \mathrm{m}$ Whatman GF/F glass-fiber filters and incubated in $90 \%$ acetone for $18 \mathrm{~h}$ in the dark at $4{ }^{\circ} \mathrm{C}$ to allow pigment extraction. The supernatant was used for $\mathrm{Chl} a$ determination with a 10AU fluorometer (Turner Designs, USA) which had been calibrated with a Chl $a$ standard from spinach (Sigma-Aldrich). 


\section{Transparent exopolymer particle concentration and visualization}

The abundance of transparent exopolymer particles (TEPs) in microalgal cultures was determined according to a dyebinding assay technique described in Passow and Alldredge (1995). TEPs are made visible through staining with alcian blue, a hydrophilic cationic dye that complexes with anionic carboyl or halfester-sulfate groups of acidic polysaccharides (Passow and Alldredge 1995). Microalgal culture samples $(0.5 \mathrm{~mL})$ were filtered $(<130$ mbar) onto $0.4-\mu \mathrm{m}$ pore-size polycarbonate filters (nucleopore track-etched membranes, Whatman). For each sample, filters were prepared in triplicate. Particles on the filter were stained for approximately $4 \mathrm{~s}$ with $1 \mathrm{~mL}$ of a $0.02 \%$ aqueous solution of Alcian Blue (8GX; Sigma-Aldrich) dissolved in $0.06 \%$ acetic acid $(0.2-\mu \mathrm{m}$-filtered, $\mathrm{pH}=2.5)$. Stained filters were rinsed with $2 \mathrm{~mL}$ ammonium formate solution $(0.47 \mathrm{M})$ to remove excess dye, transferred into centrifuge tubes, and stored at $-20{ }^{\circ} \mathrm{C}$ until further analysis. The Alcian Blue stain was extracted from the filters in $80 \%$ sulfuric acid (3-h incubation period), and the abundance was determined through spectrophotometry by measuring UV absorption at $787 \mathrm{~nm}$ (Cytation 3 Cell Imaging Multi-Mode Reader, BioTek Instruments). The concentration of TEP is expressed as concentration equivalents for the alcian blue adsorption given by standardization with the commercially available polysaccharide xanthan (X) gum (in $\mu \mathrm{g} \mathrm{X}_{\mathrm{eq}} \mathrm{mL}^{-1}$ ). The calibration protocol as described in Bittar et al.'s work (2018) was followed. When the chemical composition of TEP is unknown, the resulting TEP concentration measurements are semi-quantitative because alcian blue binds only to acidic and sulfated moieties of polysaccharides. The abundance of TEP in microalgal cultures was quantified at stationary phase for all biological replicates $(n=3)$. Measured TEP concentrations were normalized by cell density (measured with flow cytometry) to allow comparison between treatments and algal species. Microalgal culture aliquots used for TEP concentration determination were examined under the microscope (Zeiss, $40 \times$ ) for visualization of EPS abundance and distribution following alcian blue staining.

\section{Dissolved Fe concentration in the growth media}

The concentration of $\mathrm{Fe}$ in the growth medium was determined using inductively coupled plasma-mass spectrometry (Thermo Scientific Element 2 sector field ICP-MS) at the Analytical, Environmental and Geo-Chemistry research laboratories of the Vrije Universiteit Brussel. Sample preparation and analytical protocols followed are similar to those reported in Milne et al. (2010). All solutions were prepared using ultrahigh-purity water (>18 M $\Omega . c m)$ and subboiled $14 \mathrm{M} \mathrm{HNO}_{3}$. Following suitable dilution using $5 \% \mathrm{HNO}_{3}$, the concentration of Fe was determined using multiple isotopes $\left({ }^{56} \mathrm{Fe}\right.$ and $\left.{ }^{57} \mathrm{Fe}\right)$ in the medium resolution mode of the instrument. Indium was used as an internal standard and quantification took place versus an external calibration curve. The limit of detection for $\mathrm{Fe}$ is calculated to be equal to or better than $0.1 \mathrm{ppb}$ over the course of the measurement campaign. Based on the repeated measurements, the determined precision of the procedure outlined above [(standard deviation) / (average) $\times 100$ ] is better than $5-10 \%$ relative standard deviation (RSD).

\section{Estimation of growth and statistics}

Specific growth rates $(\mu)$ for microalgae cultures during exponential growth were calculated using the following equation:

$\mu=\frac{\log _{2} \frac{N_{1}}{N_{0}}}{t_{1}-t_{0}}$

where $\mu$ is in divisions per day, $t_{o}$ and $t_{l}$ determine the time interval of the exponential growth phase over which specific growth rate are being calculated (in days), $N_{o}$ is the number of algal cells at the start of the exponential phase (in cells $\mathrm{mL}^{-1}$ ), and $N_{l}$ is the cell density measured at time $t_{l}$ (Guillard 1973).

Microalgal growth rates, final cell densities, biochemical composition, and TEP concentration data in this study are expressed as means with standard error. The significance of the differences between treatments and the control upon microalgal growth rates, stationary-phase algal cell density, $\mathrm{C} / \mathrm{N}$ ratio, Chl $a$ concentration, culture TEP concentration, and algal biomass fatty acid composition and concentration was analyzed by one-way analysis of variance (ANOVA). The level of significant difference was set at $p<0.05$. Datasets analyzed conformed with the assumptions of normality and homogeneity of variance.

\section{Results}

\section{Effect of EDTA substitutes on microalgal growth and algal biomass composition}

Both microalgal species grew at rates and achieved final population densities in the range of typical performance in aquaculture settings. Nevertheless, organic metal-chelating ligands applied at equivalent dosage as EDTA in the growth medium, as well as a fivefold enhancement factor for GLU, were shown to have significant effects on the growth performance of $C$. calcitrans and T. lutea, under both static (non-bubbled) and bubbled culture conditions (Tables 1, 2, and 3; Figs. 1 and 2). Microalgal cultures remained bacteriafree throughout the course of the algal growth experiments. 
Table 1 Specific growth rate (in divisions day ${ }^{-1}$ ) of $C$. calcitrans static batch cultures in response to different chelating compounds in standard and modified F-nutrients enriched seawater

\begin{tabular}{|c|c|c|c|c|c|}
\hline Time after inoculation & 2 days & 6 days & 9 days & 14 days & 21 days \\
\hline \multirow[t]{12}{*}{ Specific growth rate (divisions day ${ }^{-1}$ ) } & GLU & GLU & GLU & GLU & EDTA \\
\hline & $1.10 \pm 0.02 *$ & $0.35 \pm 0.02 *$ & $0.27 \pm 0.02 *$ & $0.19 \pm 0.01$ & $0.17 \pm 0.02$ \\
\hline & ALG & ALG & ALG & ALG & GLU \\
\hline & $0.91 \pm 0.03 *$ & $0.31 \pm 0.01 *$ & $0.25 \pm 0.01$ & $0.17 \pm 0.01$ & $0.14 \pm 0.02$ \\
\hline & DFB & DEX & No EDTA & No EDTA & ALG \\
\hline & $0.82 \pm 0.01 *$ & $0.28 \pm 0.02$ & $0.23 \pm 0.02$ & $0.17 \pm 0.01$ & $0.13 \pm 0.03$ \\
\hline & DEX & No EDTA & EDTA & DEX & DEX \\
\hline & $0.75 \pm 0.02 *$ & $0.27 \pm 0.01$ & $0.23 \pm 0.0 .1$ & $0.17 \pm 0.02$ & $0.12 \pm 0.02$ \\
\hline & No EDTA & DFB & DEX & EDTA & No EDTA \\
\hline & $0.67 \pm 0.01 *$ & $0.26 \pm 0.02$ & $0.21 \pm 0.0 .1$ & $0.17 \pm 0.02$ & $0.11 \pm 0.01^{*}$ \\
\hline & EDTA & EDTA & DFB & DFB & DFB \\
\hline & $0.57 \pm 0.03$ & $0.25 \pm 0.02$ & $0.20 \pm 0.01$ & $0.14 \pm 0.01$ & $0.10 \pm 0.01^{*}$ \\
\hline
\end{tabular}

Experimental treatments consisted of modified F-nutrients enriched seawater wherein EDTA was substituted by the alternate chelators D-glucuronic acid (GLU), Dextran (DEX), alginic acid (ALG), or desferrioxamine B (DFB) [metal chelating ligand additives applied at a dosage of $0.23 \mu \mathrm{M}$ final culture concentration] and wherein EDTA was omitted from the F-nutrients growth media formulation (No EDTA). Culture responses to experimental treatments are compared to the control (highlighted in bold) consisting of standard F-nutrients enriched seawater (EDTA-enriched, $0.23 \mu \mathrm{M})$. Specific growth rates are reported as means \pm standard error $(n=4)$ and calculated for different time intervals of the growth curve. For each time interval, specific growth rates for control and treatment cultures are organized in descending order. Significant differences in one column relative to the control are notated with an asterisk $(p<0.05)$

Treatment effects upon culture performance (specific growth rate, stationary (final) cell density, and time required to reach stationary phase and presence/absence of a lag phase following culture inoculation) were evaluated relative to microalgal culture development using EDTA. Under static, batch-culture growth conditions, maximal increases in specific growth rate of $C$. calcitrans for all organic ligand treatments were observed in the first 2 days of culture development, ranging
Table 2 Specific growth rate (in divisions day ${ }^{-1}$ ) of $C$. calcitrans cultures grown in bubbled photobioreactors in response to different chelating compounds in standard and modified F-nutrient enriched seawater

\begin{tabular}{|c|c|c|c|c|}
\hline Time after inoculation & 2 days & 5 days & 7 days & 9 days \\
\hline Specific growth rate (divisions day ${ }^{-1}$ ) & $\begin{array}{l}{[\text { GLU-Fe] } \times 5} \\
1.55 \pm 0.05^{*} \\
\text { ALG } \\
1.54 \pm 0.06^{*} \\
{[\text { EDTA-Fe] } \times 5} \\
1.50 \pm 0.04^{*} \\
\text { GLU } \\
1.46 \pm 0.04^{*} \\
\text { DEX } \\
1.42 \pm 0.03^{*} \\
\text { EDTA } \\
\mathbf{1 . 3 5} \pm \mathbf{0 . 0 3} \\
\text { No EDTA } \\
1.03 \pm 0.02 *\end{array}$ & $\begin{array}{l}\text { ALG } \\
1.17 \pm 0.04^{*} \\
{[\text { EDTA-Fe] } \times 5} \\
1.15 \pm 0.03^{*} \\
\text { GLU } \\
1.14 \pm 0.03^{*} \\
{[G L U-F e] \times 5} \\
1.08 \pm 0.03^{*} \\
\text { DEX } \\
1.03 \pm 0.05^{*} \\
\text { EDTA } \\
\mathbf{0 . 8 4} \pm \mathbf{0 . 0 3} \\
\text { No EDTA } \\
0.61 \pm 0.03^{*}\end{array}$ & $\begin{array}{l}{[\text { GLU-Fe }] \times 5} \\
1.01 \pm 0.03 * \\
\text { GLU } \\
0.97 \pm 0.02 * \\
\text { ALG } \\
0.95 \pm 0.04^{*} \\
\text { DEX } \\
0.93 \pm 0.03^{*} \\
{[\text { EDTA-Fe } \times 5} \\
0.89 \pm 0.03^{*} \\
\text { EDTA } \\
\mathbf{0 . 7 9} \pm \mathbf{0 . 0 2} \\
\text { No EDTA } \\
0.50 \pm 0.04 *\end{array}$ & $\begin{array}{l}{[\mathrm{GLU}-\mathrm{Fe}] \times 5} \\
0.79 \pm 0.03^{*} \\
\text { GLU } \\
0.76 \pm 0.02^{*} \\
\text { ALG } \\
0.73 \pm 0.03 \\
\text { DEX } \\
0.72 \pm 0.03 \\
{[\text { EDTA-Fe] } \times 5} \\
0.70 \pm 0.02 \\
\text { EDTA } \\
\mathbf{0 . 6 2} \pm \mathbf{0 . 0 3} \\
\text { No EDTA } \\
0.39 \pm 0.02 *\end{array}$ \\
\hline
\end{tabular}

Experimental treatments consisted of modified F-nutrients enriched seawater wherein EDTA was substituted by the alternate chelators D-glucuronic acid (GLU, $0.23 \mu \mathrm{M}$ ), Dextran (DEX, $0.23 \mu \mathrm{M}$ ) or alginic acid (ALG, $0.23 \mu \mathrm{M}$ ); and for modified F-nutrients enriched seawater growth media consisting of (i) omitted EDTA in the growth media (No EDTA), (ii) factor of 5 enhanced EDTA and Fe dosage ([EDTA-Fe]' 5, $1.15 \mu \mathrm{M}]$ ) and (iii) factor of 5 enhanced GLU and Fe dosage ([GLU-Fe]' 5, $1.15 \mu \mathrm{M}$ ). Culture responses to experimental treatments are compared to the control (highlighted in bold) consisting of standard F-nutrients enriched seawater (EDTA-enriched, $0.23 \mu \mathrm{M}$ ). Specific growth rates are reported as means \pm standard error $(n=3)$ and calculated for different time intervals of the growth curve. For each time interval, specific growth rates for control and treatment cultures are organized in descending order. Significant differences in one column relative to the control are notated with an asterisk $(p<0.05)$ 
Table 3 Specific growth rate (in divisions day ${ }^{-1}$ ) of $T$. lutea static batch cultures in response to different chelating compounds in standard and modified F-nutrient enriched seawater

\begin{tabular}{|c|c|c|c|c|c|c|}
\hline Time after inoculation & 2 days & 4 days & 6 days & 9 days & 12 days & 15 days \\
\hline \multirow[t]{12}{*}{ Specific growth rate (divisions day ${ }^{-1}$ ) } & GLU & GLU & GLU & GLU & GLU & No EDTA \\
\hline & $1.06 \pm 0.02 *$ & $0.80 \pm 0.02 *$ & $0.61 \pm 0.01$ & $0.45 \pm 0.02$ & $0.35 \pm 0.02$ & $0.29 \pm 0.02$ \\
\hline & ALG & DEX & DEX & EDTA & DEX & GLU \\
\hline & $0.92 \pm 0.01 *$ & $0.70 \pm 0.02$ & $0.60 \pm 0.01$ & $0.45 \pm 0.02$ & $0.34 \pm 0.01$ & $0.28 \pm 0.01$ \\
\hline & DEX & EDTA & EDTA & DEX & EDTA & EDTA \\
\hline & $0.87 \pm 0.01 *$ & $0.66 \pm 0.01$ & $0.60 \pm 0.02$ & $0.41 \pm 0.02$ & $0.34 \pm 0.02$ & $0.27 \pm 0.01$ \\
\hline & EDTA & ALG & No EDTA & No EDTA & No EDTA & DEX \\
\hline & $0.79 \pm 0.02$ & $0.65 \pm 0.02$ & $0.55 \pm 0.02$ & $0.40 \pm 0.01$ & $0.32 \pm 0.01$ & $0.27 \pm 0 . x x$ \\
\hline & No EDTA & No EDTA & DFB & ALG & ALG & ALG \\
\hline & $0.75 \pm 0.02$ & $0.60 \pm 0.02$ & $0.46 \pm 0.03^{*}$ & $0.40 \pm 0.01 *$ & $0.31 \pm 0.01$ & $0.25 \pm 0.01$ \\
\hline & DFB & DFB & ALG & DFB & DFB & DFB \\
\hline & $0.67 \pm 0.02 *$ & $0.54 \pm 0.02 *$ & $0.40 \pm 0.01 *$ & $0.32 \pm 0.02 *$ & $0.27 \pm 0.02 *$ & $0.22 \pm 0.01 *$ \\
\hline
\end{tabular}

Experimental treatments consist of adapted F-nutrients enriched seawater wherein EDTA was substituted by the alternate chelators D-glucuronic acid (GLU), Dextran (DEX), alginic acid (ALG) or desferrioxamine B (DFB) [metal chelating additives applied at a dosage of $0.23 \mu \mathrm{M}$ final culture concentration]; and wherein EDTA was omitted from the F-nutrients growth media formulation (No EDTA). Culture responses to experimental treatments are compared to the control (highlighted in bold) consisting of standard F-nutrients enriched seawater (EDTA-enriched, 0.23 $\mu \mathrm{M})$. Specific growth rates are reported as means \pm standard error $(n=4)$ and and calculated for different time intervals of the growth curve. For each time interval, specific growth rates for control and treatment cultures are organized in descending order. Significant differences relative to the control are notated with an asterisk $(p<0.05)$

between a $93 \%$ increase (for GLU treatments) to $32 \%$ (for DEX treatments) (Table 1). Logarithmic microalgal growth

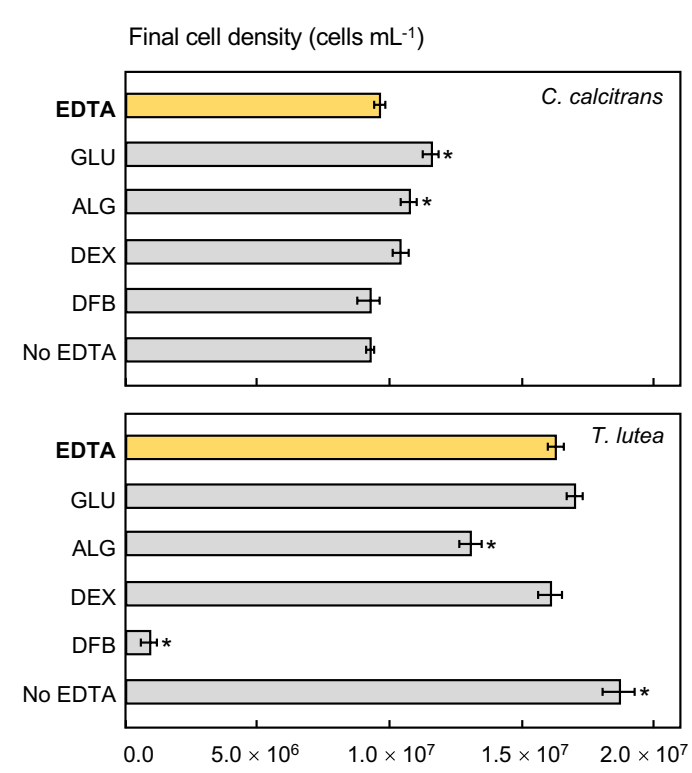

Fig. 1 Stationary-phase cell density and percent change in maximal cell density relative to the control of $C$. calcitrans and $T$. lutea static batch cultures in response to different chelating compounds in standard and modified F-nutrient-enriched seawater. The control treatment consists of standard F-nutrient-enriched seawater (EDTA-chelated; highlighted in yellow and bold). Experimental treatments consisted of modified F-nutrients enriched seawater wherein EDTA was substituted by the alternate chelators D-glucuronic acid (GLU), dextran (DEX), alginic acid (ALG), or desferrioxamine B (DFB) (metal- with candidate chelators was maintained over the first 9 days of culture development, with an averaged specific growth

Percent change in maximum cell density

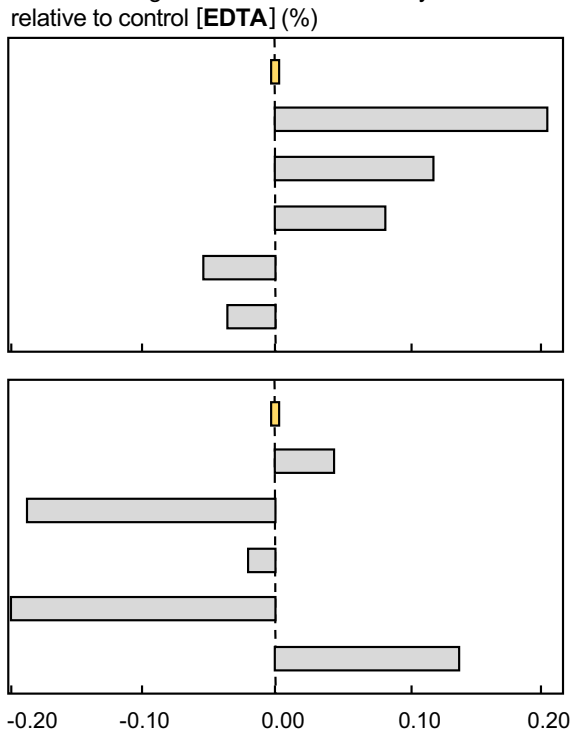

chelating ligand additives applied at a dosage of $0.23 \mu \mathrm{M}$ final culture concentration) and wherein EDTA was omitted from the F-nutrients growth media formulation (No EDTA). Values are reported as means \pm standard error $(n=4)$. Significant differences relative to the control are notated with an asterisk $(p<0.05)$. Maximal cell densities were reached after a 21- and 15-day culture period for $C$. calcitrans and T. lutea, respectively. Vertical dotted lines delineate no statistically significant difference in final cell density relative to the control 


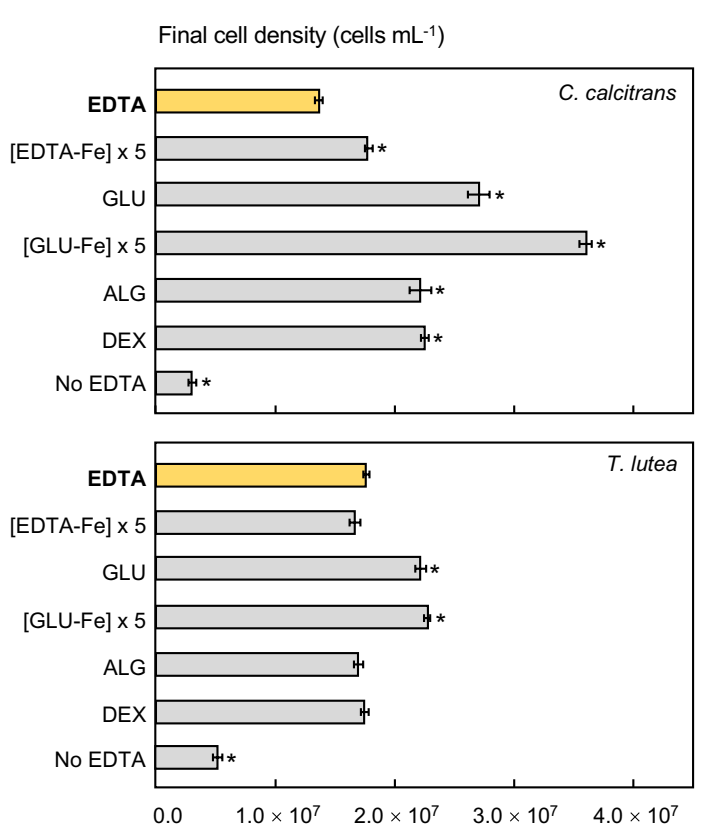

Factorial change in maximum cell density

relative to control [EDTA]
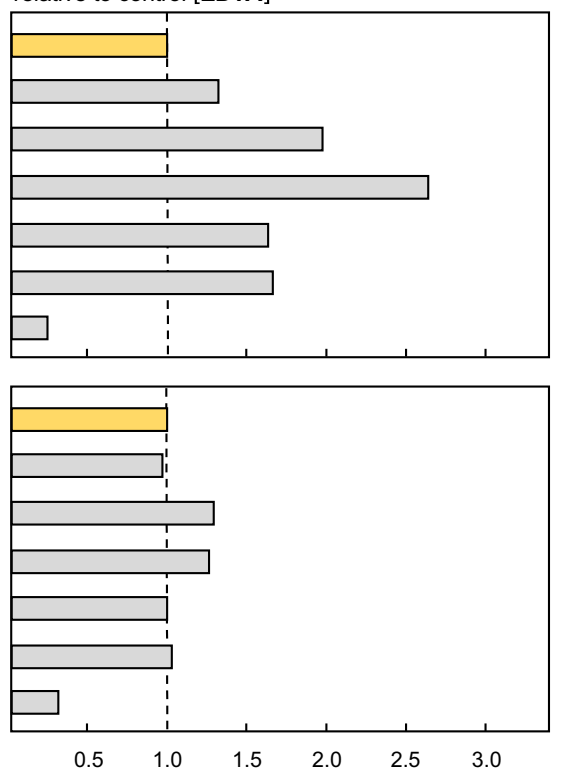

Fig. 2 Stationary-phase cell density and factorial change in maximal cell density relative to the control of $C$. calcitrans and T. lutea cultures grown in bubbled photobioreactors in response to different chelators in standard and modified F-nutrient-enriched seawater. The control treatment consists of standard F-nutrients enriched seawater (EDTA-enriched; highlighted in yellow and bold). Experimental treatments consisted of modified F-nutrient-enriched seawater wherein EDTA $(0.23 \mu \mathrm{M})$ was substituted by the alternate chelators D-glucuronic acid (GLU, $0.23 \mu \mathrm{M}$ ), dextran (DEX, $0.23 \mu \mathrm{M}$ ), or alginic acid (ALG, $0.23 \mu \mathrm{M}$ ); and for modified F-nutrients enriched

rate amplification of $18 \%$ over EDTA for GLU treatments. For the final fraction of the exponential growth phase (from day 9 until stationary phase), organic ligand and EDTA treatments supported similar growth characteristics. Chaetoceros calcitrans grown in adapted F-nutrient-enriched seawater medium devoid of external EDTA also exhibited a statistically significant increase (17\%) in specific growth rate relative to standard growth medium (complete F-nutrients suite) during the early exponential growth phase. In combination with increased specific growth rates, final cell yields of $C$. calcitrans were enhanced by $20 \%$ and $12 \%$ in the GLU and ALG treatments, respectively (Fig. 1). Similarly, specific growth rates for $C$. calcitrans cultures grown in bubbled photobioreactors were significantly increased over EDTA cultures in the presence of alternate chelators (Table 2). A maximum specific growth rate amplification of $\sim 20 \%$, when averaged over the 9-day exponential growth phase, was recorded for GLU and ALG treatments. Final cell densities for $C$. calcitrans cultures in bubbled photobioreactors were markedly enhanced in the presence of candidate metal chelators by $2.0-2.5$ times (Fig. 2). seawater growth media consisting of (i) omitted EDTA in the growth media (No EDTA), (ii) factor of 5 enhanced EDTA and Fe dosage ([EDTA-Fe $\times 5$ ], $1.15 \mu \mathrm{M}$ ), and (iii) factor of 5 enhanced GLU and $\mathrm{Fe}$ dosage $([\mathrm{GLU}-\mathrm{Fe} \times 5], 1.15 \mu \mathrm{M})$. Values are reported as means \pm standard error $(n=3)$. Significant differences relative to the control are notated with an asterisk $(p<0.05)$. Maximal cell densities were reached after a 9- and 8-day culture period for $C$. calcitrans and T. lutea, respectively. Vertical dotted lines delineate no statistically significant difference in final cell density relative to the control

Static batch cultures of T. lutea also were positively affected by candidate chelators, with the exception of DFB which inhibited growth (Table 3). Specific growth rate amplifications in response to alternate chelator additions were most notable in the early stages of the exponential growth phase, with GLU and ALG treatments supporting increases of 15 and 34\%, respectively. Tisochrysis lutea culture performance in EDTA and alternate chelator treatments converged to similar growth characteristics as cultures approached mid-exponential phase. In static and bubbled bioreactor culture conditions, a lag phase in the initial stage of culture development (from inoculation until day 2) of $T$. lutea in the presence of EDTA was observed. No lag phase in culture development following inoculation was observed for other evaluated candidate metal-chelator treatments. Tisochrysis lutea cultures grown in modified F-nutrientenriched seawater devoid of external EDTA showed statistically significant reduced growth relative to the EDTA control. Substitution of EDTA with candidate chelators in static batch cultures had no statistically significant effect upon final cell yield of $T$. lutea cultures, except for the ALG 
treatment wherein a $20 \%$ decrease in final cell density was observed (Fig. 1). In contrast, final cell densities of T. lutea grown in bubbled reactors were not negatively affected by inclusion of ALG in the medium and were amplified by $27 \%$ in the presence of GLU (dosage independent) (Fig. 2).

In both microalgal species examined, a distinct GLU $>$ ALG $>$ DEX > DFB trend in growth stimulation (for both static and photobioreactor batch cultures) was observed. Increasing the dosage of the organic ligand in the growth medium by an order of magnitude, based upon the recommended metal chelator dosage in the F-nutrientenriched seawater growth medium formulation, had no effect on microalgae growth (for GLU and DEX) and resulted in growth inhibition (for DFB and ALG) and precipitate formation for ALG treatments. Enhancing the GLU and Fe dosage by a factor 5 relative to recommended dosage for F-nutrients in the growth medium of the bubbled photoreactors resulted in no statistically significant increase in specific growth rate of $C$. calcitrans cultures relative to the standard GLU dosage; however, there was a dosage-dependent increase in final cell yields relative to the EDTA control (factor of 2.0 increase for standard GLU and Fe dosage, compared to a factor of 2.7 increase for (GLU-Fe) $\times 5$ dosage) (Fig. 2).

Experimental treatments consisted of modified F-nutrient-enriched seawater wherein EDTA was substituted by the alternate chelators D-glucuronic acid (GLU), dextran (DEX), alginic acid (ALG), or desferrioxamine B (DFB) (metalchelating ligand additives applied at a dosage of $0.23 \mu \mathrm{M}$ final culture concentration) and wherein EDTA was omitted from the F-nutrient growth media formulation (No EDTA). Culture responses to experimental treatments are compared to the control (highlighted in bold) consisting of standard F-nutrients enriched seawater (EDTA-enriched, $0.23 \mu \mathrm{M}$ ). Specific growth rates are reported as means \pm standard error $(n=4)$ and calculated for different time intervals of the growth curve. For each time interval, specific growth rates for control and treatment cultures are organized in descending order. Significant differences in one column relative to the control are notated with an asterisk $(p<0.05)$.

Experimental treatments consisted of modified F-nutrient-enriched seawater wherein EDTA was substituted by the alternate chelators D-glucuronic acid (GLU, $0.23 \mu \mathrm{M}$ ), dextran (DEX, $0.23 \mu \mathrm{M}$ ). or alginic acid (ALG, $0.23 \mu \mathrm{M}$ ); and for modified F-nutrient-enriched seawater growth media consisting of (i) omitted EDTA in the growth media (No EDTA), (ii) factor of 5 enhanced EDTA and Fe dosage $(($ EDTA-Fe $) \times 5,1.15 \mu \mathrm{M})$, and (iii) factor of 5 enhanced GLU and Fe dosage $([\mathrm{GLU}-\mathrm{Fe}] \times 5,1.15 \mu \mathrm{M})$. Culture responses to experimental treatments are compared to the control (highlighted in bold) consisting of standard F-nutrient-enriched seawater (EDTA-enriched, $0.23 \mu \mathrm{M}$ ). Specific growth rates are reported as means \pm standard error $(n=3)$ and calculated for different time intervals of the growth curve. For each time interval, specific growth rates for control and treatment cultures are organized in descending order. Significant differences in one column relative to the control are notated with an asterisk $(p<0.05)$.

Experimental treatments consist of adapted F-nutrient-enriched seawater wherein EDTA was substituted by the alternate chelators D-glucuronic acid (GLU), dextran (DEX), alginic acid (ALG), or desferrioxamine B (DFB) (metal-chelating additives applied at a dosage of $0.23 \mu \mathrm{M}$ final culture concentration), and wherein EDTA was omitted from the F-nutrient growth media formulation (No EDTA). Culture responses to experimental treatments are compared to the control (highlighted in bold) consisting of standard F-nutrient-enriched seawater (EDTA-enriched, $0.23 \mu \mathrm{M})$. Specific growth rates are reported as means \pm standard error $(n=4)$ and calculated for different time intervals of the growth curve. For each time interval, specific growth rates for control and treatment cultures are organized in descending order. Significant differences relative to the control are notated with an asterisk $(p<0.05)$.

The stoichiometric C:N ratio of C. calcitrans and T. lutea harvested towards the end of the log phase for the control cultures averaged $7.18 \pm 0.11$ and $5.12 \pm 0.42$, respectively (Table 4). Substitution of EDTA with alternate metal-chelating compounds had no statistically significant effect upon cellular C:N ratio at stationary phase. Similarly, enhanced Fe and metal chelator (EDTA and GLU) dosage in the growth medium had no effect on cellular C:N ratio. Stationary-phase cellular $\mathrm{Chl} a$ concentration for $C$. calcitrans cultures grown in the GLU-containing growth media were significantly enhanced by $\sim 24 \%$ relative to EDTA-enriched cultures, irrespective of GLU dosage (Table 4). Other candidate metal chelators in C. calcitrans cultures had no statistically significant effect upon cellular Chl $a$ concentration. Substitution of EDTA with alternate chelators had no detectable effect on cellular Chl $a$ levels of T. lutea cultures.

Chaetoceras calcitrans biomass harvested at stationary phase was characterized by a total fatty acid content of 96.24 $\pm 1.27 \mathrm{mg}$ FAME g $^{-1}$ dry weight in EDTA- and GLUenriched cultures (Table 4). A 22\% decrease in total fatty acid content for $C$. calcitrans was observed for ALG and DEX treatments, mainly driven by decreased saturated and monounsaturated fatty acid content. A dosage-dependent increase of 27 to $32 \%$ over EDTA-enriched cultures in C. calcitrans omega-3 polyunsaturated fatty acid (PUFA) content was observed in GLU treatments. Increased GLU dosage in the growth medium was paired with an increased algal omega-3 PUFA content. No statistically significant change in $C$. calcitrans omega-3 PUFA content was observed for DEX and ALG. Total fatty acid content and omega-3 PUFA content 


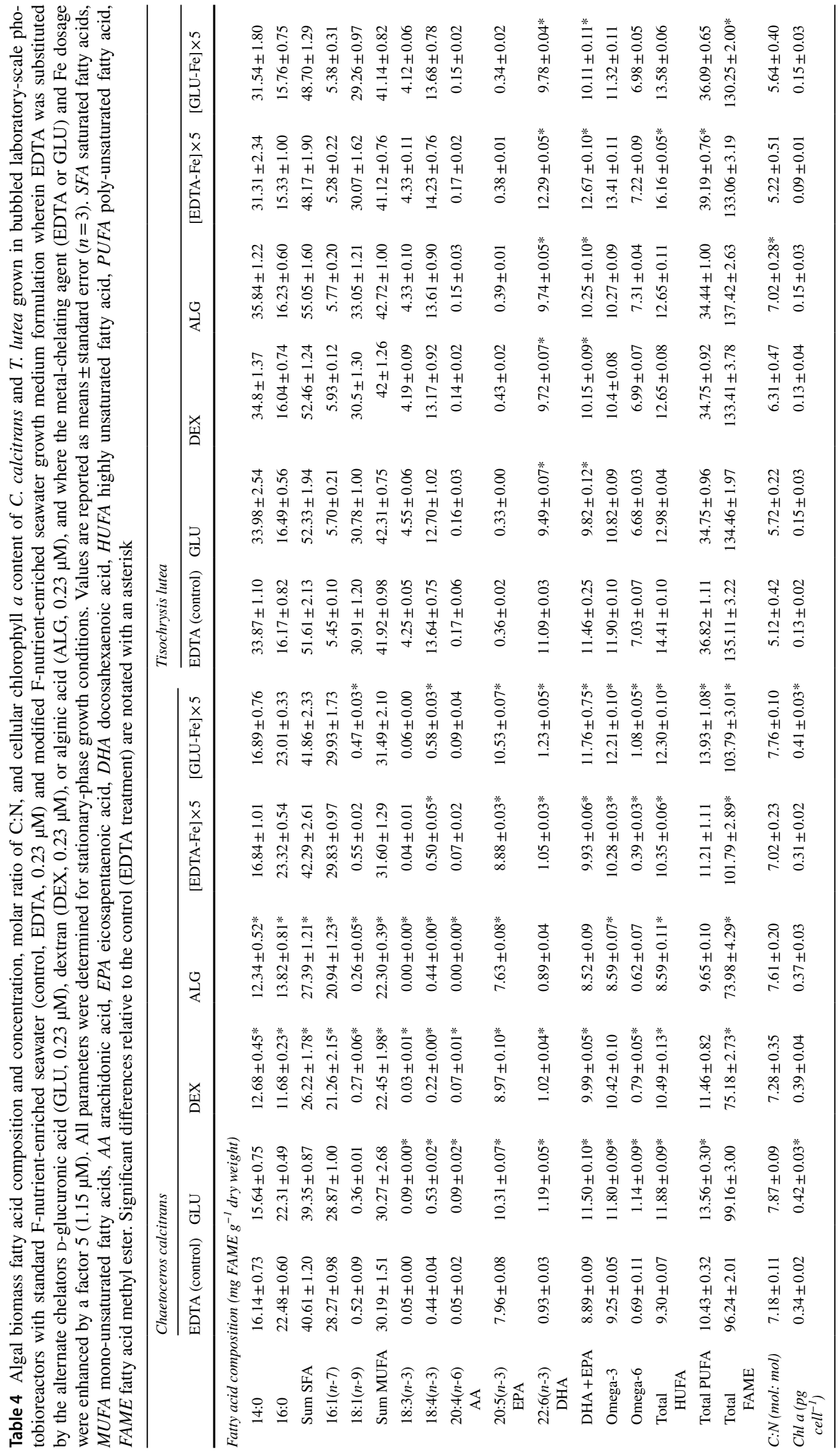


Fig. 3 Transparent exopolymer particle (TEP) distribution in stationary-phase Tisochrysis lutea cultures exposed to different chelating compounds in standard and modified F-nutrient-enriched seawater (static batch culture growth conditions). TEPs were made visible through alcian blue staining of the anionic carboyl or halfester-sulfate groups of acidic polysaccharides. A, B EDTA (control). C F-nutrients growth media formulation devoid of EDTA (No EDTA).

D desferrioxamine B (DFB). E D-Glucuronic acid (GLU). F, G Alginic acid (ALG). H Dextran (DEX)
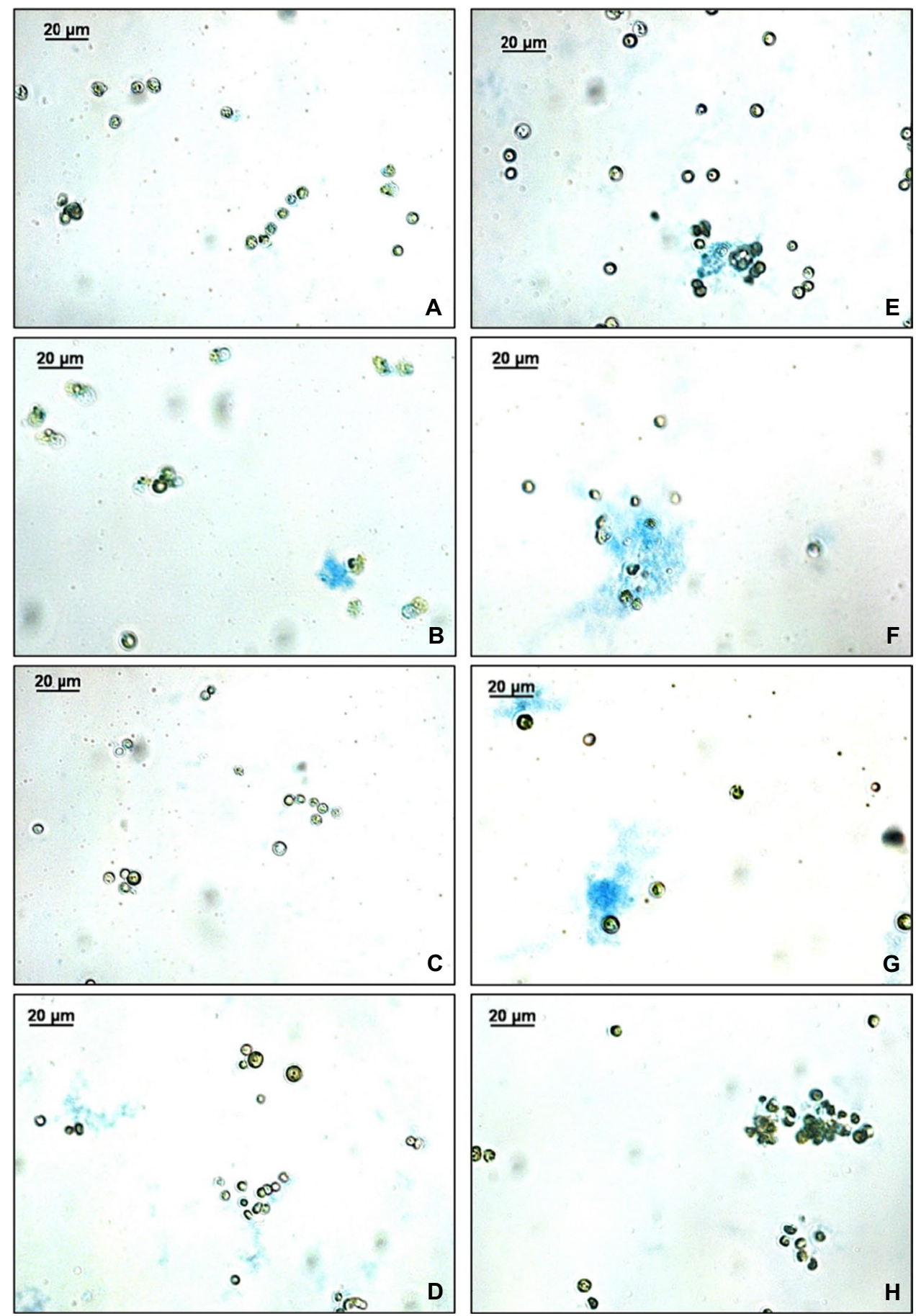

in $T$. lutea cultures averaged $135.11 \pm 2.13$ and $11.90 \pm 0.72$, respectively, and was not affected by the choice of metalchelating agent and applied dosage in the growth medium.

Independent of the metal-chelator compound considered in the growth medium (control or experimental treatments), no statistically significant difference in measured dissolved Fe concentrations in the growth medium prior inoculation was observed. Dissolved Fe concentrations at the onset of algal culture experiments were $0.23 \pm 0.03 \mu \mathrm{M}$ for control and alternate chelator candidates, applied at equivalent dosage. The measured abundance of TEP in the growth media prior inoculation was below limit of detection across control and experimental treatments.

Depending upon the metal-chelating agent present in the growth media (control or treatments), microscopic examination of T. lutea cultures, grown in static conditions, showed a different abundance of alcian blue-stained particles indicative for polysaccharide-containing TEP. 
Table 5 Transparent exopolymer particle (TEP) concentration and microalgal-cell normalized abundance of TEP of $C$. calcitrans and T. lutea cultures grown in bubbled photobioreactors in response to different chelating compounds in standard and modified F-nutrient-enriched seawater. Culture samples were harvested at station- ary phase following 8 days of cultivation. TEP abundances are expressed in mass xanthan $(\mathrm{X})$ gum equivalent. Values are reported as means \pm standard error $(n=3)$. Significant differences relative to the control are notated with an asterisk $(p<0.05)$

\begin{tabular}{|c|c|c|c|c|}
\hline & \multicolumn{2}{|c|}{ Chaetoceros calcitrans } & \multicolumn{2}{|l|}{ Tisochrysis lutea } \\
\hline & $\begin{array}{l}\text { TEP culture } \\
\left(\mu \mathrm{g} X \text { eq. } \mathrm{mL}^{-1}\right)\end{array}$ & $\begin{array}{l}\text { TEP per cell (pg X eq. } \\
\text { cell }^{-1} \text { ) }\end{array}$ & $\begin{array}{l}\text { TEP culture } \\
\left(\mu \mathrm{g} X \text { eq. } \mathrm{mL}^{-1}\right)\end{array}$ & $\begin{array}{l}\text { TEP per cell } \\
\left(\mathrm{pg} \mathrm{X}^{\mathrm{eq}} \text {. }\right. \\
\left.\left.\mathrm{cel}^{\mathrm{l}}\right)^{-1}\right)\end{array}$ \\
\hline EDTA (control) & $23.42 \pm 2.32$ & $1.71 \pm 0.33$ & $13.01 \pm 1.18$ & $0.74 \pm 0.07$ \\
\hline$[$ EDTA-Fe] $\times 5$ & $25.10 \pm 3.17$ & $1.40 \pm 0.10$ & $12.55 \pm 3.02$ & $0.75 \pm 0.21$ \\
\hline GLU & $42.57 \pm 2.07 *$ & $1.57 \pm 0.38$ & $24.89 \pm 1.68 *$ & $1.11 \pm 0.73^{*}$ \\
\hline$[\mathrm{GLU}-\mathrm{Fe}] \times 5$ & $59.72 \pm 4.10 *$ & $1.65 \pm 0.47$ & $29.86 \pm 2.92 *$ & $1.35 \pm 0.53^{*}$ \\
\hline ALG & $67.60 \pm 3.02 *$ & $3.03 \pm 0.12 *$ & $42.11 \pm 4.21 *$ & $2.42 \pm 0.60^{*}$ \\
\hline DEX & $26.89 \pm 1.08 *$ & $1.18 \pm 0.30$ & $12.72 \pm 1.81$ & $0.72 \pm 0.34$ \\
\hline No EDTA & $15.26 \pm 1.92 *$ & $4.05 \pm 0.41 *$ & $14.37 \pm 2.42$ & $2.81 \pm 0.17 *$ \\
\hline
\end{tabular}

Abundant and large $(>20 \mu \mathrm{m})$ TEPs were present in the culture media of GLU and ALG treatments (Fig. 3). Smaller $(<20 \mu \mathrm{m})$ and less abundant TEPs are observed in the control (EDTA-chelated) F-nutrient-enriched seawater treatment. In DFB and DEX treatments and microalgal cultures devoid of externally added metal-chelating agent (No EDTA), no significant amounts of alcian blue stainable TEPs were visualized. Colorimetric determination of TEP abundances in $C$. calcitrans cultures grown in bubbled photobioreactors ranged between $67.6 \mu \mathrm{g} \mathrm{X}$ eq. $\mathrm{mL}^{-1}$ for ALG; $23.4 \mu \mathrm{g} \mathrm{X} \mathrm{eq.} \mathrm{mL}^{-1}$ for the EDTA (control treatment); and $12.3 \mu \mathrm{g} \mathrm{X}$ eq. $\mathrm{mL}^{-1}$ in the absence of an external metal-chelating agent in the culture media (Table 5). TEP abundances in T. lutea cultures were systematically lower relative to TEP abundances for the diatom species when comparing equivalent treatments. Maximal TEP abundances in T. lutea cultures were equally observed for ALG treatments $\left(42.1 \mu \mathrm{g} \mathrm{X}\right.$ eq. $\left.\mathrm{mL}^{-1}\right)$, representing over a factor of 3 increase relative to the control (EDTA) treatment.

\section{Discussion}

\section{General findings}

Substitution of EDTA with organic metal-chelating ligands in the growth media of two model marine microalgae species ( $C$. calcitrans and $T$. lutea) cultivated in static batch cultures and in bubbled photobioreactors generally had no detrimental effects on culture development and in some cases improved microalgal culture characteristics (specific growth rate and final cell density) as well as algal nutritional profile (omega-3 PUFA and Chl $a$ content). Observed effects of EDTA substitution with alternate metal-chelating compounds were dependent upon culture condition, microalgal species, chelator type, and dosage. Inclusion of alternate chelators in the growth media induced a generally more pronounced culture response for $C$. calcitrans, relative to $T$. lutea, in terms of specific growth rate and final cell yield enhancement, as well as on algal biochemical composition alteration. In both microalgal species and both culturing types (batch and photobioreactor), microalgal growth stimulation by EDTA alternatives examined in this study consistently followed a GLU $>$ ALG $>$ DEX $>$ DFB trend in culture response (with the exception of DFB with T. lutea, wherein reduced growth relative to EDTA was observed).

Collectively, our results (i) emphasize the sub-optimal growth conditions provided by EDTA-chelated growth media for microalgal cultivation, and (ii) show that inclusion of candidate alternative chelators in growth medium formulations may represent a promising strategy to reduce the use of non-biodegradable chelators such as EDTA in microalgae cultivation practices while providing growth acceleration and algal biomass nutritional profile enhancement. Several physiological and ecological mechanisms may underlie our observations.

\section{Effect of alternate metal-chelating compounds upon microalgal growth and biomass composition}

Synthetic aminopolycarboxylates, such as EDTA, are used widely in microalgal culture media formulations as trace metal ion-chelating agents (Gerringa et al. 2000; Sunda et al. 2005). Although EDTA is effective at controlling speciation of free metal ions in growth media, sub-optimal growth conditions for the microalgal species examined in this study were observed relative to several alternatives. These observations are consistent with reported sub-optimal growth related to lower Fe bioavailability and Fe uptake for 
the cultivation of plants (i.e., rice seedlings) and coastal microalgal species (i.e., Heterosigma akashiwo, Prymnesium parvum, and Skeletonema marinodohrnii complex) when EDTA was used as the metal chelator in the hydroponic or microalgal growth medium, compared to when EDTA was replaced by HIDS, a biodegradable chelator (Hasegawa et al. 2012; 2018). In the present study, substitution of EDTA with several organic alternatives increased microalgal growth rates, especially in the initial days following culture inoculation, for C. calcitrans and T. lutea. Observed effects of organic metal-chelating ligands upon algal growth are likely related to metal bioavailability.

At a fundamental level, the conditions that control Fe bioavailability include the physical state (precipitate, colloidal, or soluble) and chemical speciation (free, organically bound, mineral bound) of the element, combined with biological cellular Fe requirements and Fe-uptake pathways (Bruland et al. 1991; Sunda and Huntsman 1995b; Worms et al. 2006; Shaked and Lis 2012). Complexation of Fe with metalchelating ligands $(\mathrm{L})$ [ $\mathrm{Fe}-\mathrm{L}$ complex] solubilizes ferric $\mathrm{Fe}$ in the growth medium. Ligand concentration and stability constants of $\mathrm{Fe}-\mathrm{L}$ complexes $(K \mathrm{Fe}-\mathrm{L})$ are important factors determining $\mathrm{Fe}$ solubility in the growth medium and also influence the bioavailability and uptake of Fe in plants and phytoplankton (Hassler and Schoemann 2009; Hasegawa et al. 2018). The candidate ligands examined in this study cover a range of molecule sizes, physiochemical properties, and Fe-chelating strengths. Chelating organic ligands commonly are categorized into two classes, operationally defined as $\mathrm{L} 1$ and L2, based upon relative binding affinities with $\mathrm{Fe}$ (Hunter and Boyd 2007). Strong binding ligands, L1, such as the hydroxamate siderophore desferrioxamine B (DFB), have affinity for $\mathrm{Fe}$ similar to those of bacterial siderophores, whereas L2 class ligands have weaker binding capacity (Rue and Bruland 1997; Gledhill and Buck 2012). Saccharides, such as GLU, DEX, and ALG, are considered to be L2 class ligands. Iron in the presence of weaker ligand classes (L2) is stabilized within the dissolved phase, predominantly in inorganic $\left(\mathrm{Fe}^{3+}, \mathrm{Fe}(\mathrm{OH})_{2+}, \mathrm{Fe}(\mathrm{OH})^{+}{ }_{2}\right)$ and colloidal form of Fe that are highly bioavailable (chemically labile) (Hassler et al. 2011). In contrast, siderophores are characterized by a high affinity constant for $\mathrm{Fe}(\mathrm{III})$, and efficiently compete for organically bound Fe(III) (Croot et al. 2004; Maldonado et al. 2005). As such, L1 class ligands like DFB can inhibit microalgal growth, as observed in this study, which is probably attributable to the competitive behavior of complexation of Fe(III)-L in the medium and Fe uptake by phytoplankton (Shaked and Lis 2012).

In the present study, at equivalent dosage the effect of weaker binding ligands GLU $>$ ALG $>$ DEX for both model microalgae examined was consistent with expectations based on the respective $\mathrm{KFe}-\mathrm{L}$ of these compounds. The efficiency of GLU, relative to ALG and DEX, in promoting Fe solubility and enhanced $\mathrm{Fe}$ algal uptake has been observed in several groups of eukaryotic polar phytoplankton in both cultured and natural settings (Hassler and Schoemann 2009; Hassler et al. 2011). The uronic acid, glucuronic acid (GLU, a monosaccharide), is a major constituent in the EPS of heterotrophic and autotrophic microbes, such as the haptophytes Emiliania huxleyi and Phaeocystis (Hoagland et al. 1993; Nichols et al. 2005). Hassler et al. (2011) demonstrated that the presence of GLU $(5 \mathrm{nM})$ in the growth medium increased the Fe uptake rate by eukaryotic phytoplankton (Chaetoceros sp. and Phaeocystis sp.) by 2.3-fold (Hassler et al. 2011), highlighting increased iron bioavailability resulting from saccharides forming highly bioavailable organic associations with iron and increasing iron solubility. Our observations of increased algal growth in the presence of organic metalchelating ligands in the growth medium of two "domesticated" marine microalgal species show that the influence of these organic compounds on microalgal culture performance is a common phenomenon that goes beyond enhancing $\mathrm{Fe}$ solubility in oxic environments and represents an opportunity for improved commercial production of microalgae.

Inclusion of L2 organic ligands in the growth medium resulted in microalgal species-dependent growth responses, with $C$. calcitrans grown with GLU showing the most promising improvement over EDTA. Based upon the Fe uptake model for eukaryotic phytoplankton in the presence of L2 chelating ligands, it is inferred that dissolved Fe(III) species in the growth medium may become precipitated on the algal cells as colloidal forms of $\mathrm{Fe}$ (denoted as $\left.\mathrm{Fe}(\mathrm{IIII})^{\prime}\right)$ that facilitate algal Fe uptake (Hasegawa et al. 2018). Prior to intracellular Fe uptake, $\mathrm{Fe}(\mathrm{III})^{\prime}$ species supplied on the cell surface are transformed into suitable forms (biologically mediated reduction of $\mathrm{Fe}(\mathrm{III})$ compounds by reductases located on the cell surface) and subsequently transported across the cell membrane (Anderson and Morel 1982; Marchetti et al. 2006). Weak ligands, such as the saccharides examined in this study, have been shown to facilitate access of phytoplankton to Fe by more readily disassociating and releasing Fe(III)' to the cell surface (Hassler et al. 2011, 2015). Iron acquisition for phytoplankton is biologically mediated through highly species-dependent uptake transport systems often involving the reduction of Fe(III)' (Shaked and Lis 2012). Generally, diatoms are known to use a surface reductase that reduces $\mathrm{Fe}$ (III) organically bound to the cell surface, thus favoring the subsequent dissociation of the Fe(II) complex and $\mathrm{Fe}$ internalization (Shaked et al. 2005). The varying culture response following exposure to a series of organic ligands for the two microalgal species examined in this study are likely partly attributable to (i) Fe uptake strategy differences between the microalgal species examined for both ferric and ferrous iron $\mathrm{Fe}$ and/or involved ferrireductase 
system, or (ii) different Fe-binding capacity of the cell surface before uptake of Fe.

GLU significantly increased algal growth and final cell density for both microalgal species examined in this study. For $C$. calcitrans, inclusion of GLU also significantly increased final cell yield and EPS abundance in the culture and enhanced the Chl $a$ and omega 3-PUFA contents of algal biomass. Enhanced microalgal growth, combined with increased yield, indicates that in the alternate-chelatorsupplemented growth medium, more nutrient and carbon are bioavailable for microalgal assimilation. In regard to the higher chlorophyll contents, $\mathrm{Fe}$ is an essential element for chlorophyll biosynthesis, acting in elementary enzymatic reactions of photosystems I and II (Sun et al. 2014). Accordingly, increased algal growth may reflect proficient photosynthetic performance in the presence of GLU-Fe chelation. Enhancement of the PUFA content of algal biomass, and specifically omega-3 PUFAs, is essential to improve the quality of algal biomass feedstock in various industries (Tocher 2015). Although enhanced fatty acid and lipid productivity are often obtained under nutrient $(\mathrm{N}, \mathrm{Fe})$ stress conditions (Singh et al. 2015), increased biomass production and lipid content of the microalgae Chlorella vulgaris and Scenedesmus obliquus were reported when the medium was supplemented with high Fe concentration (Liu et al. 2008; Abd El Baky et al. 2012).

A significant increase in final cell density was observed for both model microalgae species examined in the presence of GLU in the growth medium, with a more pronounced (and dosage-dependent) effect in C. calcitrans (up to a factor 2-2.5 increase in yield) relative to T. lutea (25\% increase). Glucuronic acid is the uronic acid analog of glucose. Consequently, enhanced final cell yields could partly be explained by mixotrophy (use of phototrophy and heterotrophy in combination) using organic substrates in the growth media (Burkholder et al. 2008). The marine green microalgae Tetraselmis suecica and diatom Cyclotella cryptica have recently been shown capable of mixotrophic growth on glycerol, glucose, and acetate (Smith et al. 2020). Similarly, the diatom Phaeodactylum tricornutum can be cultured mixotrophically in the presence of glycerol resulting in fourfold increases in final cell density compared to photoautotrophic culture (Smith et al. 2020). The varying effect of GLU upon final cell yield of $C$. calcitrans and T. lutea in our experiments likely reflects a species-dependent ability for the uptake of organic substrates. Collectively, our observations show that the effect of substitution of EDTA with several organic metal-chelating ligands extends beyond maintaining optimal Fe solubility in the growth medium, with beneficial effects on maximal cell yield and algal biomass composition.

Organic complexation of Fe with EPS is essential for the biogeochemical cycling of $\mathrm{Fe}$ in the oceans (Hassler et al., 2015). Distinct 5-20 $\mu \mathrm{m}$ TEPs were visualized in stationary-phase T. lutea cultures in the presence of GLU and ALG and were less obvious in other evaluated chelator compounds (control and treatments). Stationary-phase gross TEP concentrations in C. calcitrans and T. lutea cultures in the presence of GLU and ALG were markedly higher relative to the control and other examined candidate chelators. Accordingly, cell normalized TEP abundances were significantly enhanced for both microalgae species in the presence of ALG, and in the presence of GLU for T. lutea cultures. Observed TEP abundances are likely of algal origin given the below detectable levels of TEP in the growth medium prior inoculation. These saccharide-rich TEPs interfere with metal bioavailability as formerly observed for closely related EPS compounds (Hassler et al. 2011). The paired increased microalgal culture performance and algal EPS production in the presence of GLU and ALG implies a potential role of these compounds in the stimulation of algal EPS production, enhancing iron bioavailability and correspondingly algal growth. The absence of detectable differences in measured dissolved Fe concentrations in the growth media at the onset of algal growth experiments imply that observed difference in microalgal culture performance is not related to initial dissolved $\mathrm{Fe}$ levels in the growth media, and likely partly controlled by the in situ EPS budget and EPS-Fe complexation dynamics.

The omission of metal chelators addition in the growth medium of $C$. calcitrans cultures grown in static batch culture conditions had no detrimental effect on algal growth and resulted in statistically similar final cell yields at stationary phase relative to the control. These observations imply the presence of sufficient naturally occurring metal-chelating compounds in the algal inoculum or originating from organic carbon impurities on the culture flasks, to support microalgal growth.

Similarly, consideration of the contribution of these organic compounds in microalgal cultivation is relevant to our understanding of $\mathrm{Fe}$ nutrition and has a series of practical implications for the optimization of microalgal cultivation practices. Upon inoculation, growth lag and fail are a concern and likely result from sub-optimal bioavailability of essential metals associated with low dissolved organic matter levels following conditioning (filtration, pasteurization, autoclaving, or oxidation with hypochlorite or UV light) of growth media. Furthermore, the amount of natural chelating compounds in unconditioned (unheated and unsterilized) seawater is $10,000 \mathrm{X}$ too dilute to balance macronutrient concentrations in media formulations and anticipated final cell abundances. Sub-optimal growth conditions in the presence of EDTA (with no inclusion of external organic ligands) in our experiments show a lag phase in cultures of $T$. lutea and significantly slower growth for both species examined, particularly in the initial days of culture development. In this context, the present study demonstrates that 
balancing organic metal-chelating compounds in growth media formulations is an important component for maximizing growth and preventing potential culture failures.

\section{Implications for aquaculture live-feed production and cellular agriculture}

Attractive biochemical compositional features and rapid growth rates confer on marine microalgae significant promise for the production of whole-cell aquaculture live feeds and functional feed ingredients, as well as other valuable chemicals with broad biotechnology applications (Yarnold et al. 2019). The ability to achieve high cell yields of strains with high nutritional value (elevated lipid or omega-3-PUFA content), and rapid growth rates, is a key requirement to achieve large-scale, economically viable microalgal production (Khan et al. 2018). The present study demonstrates that the benefits of substituting EDTA, or other synthetic aminopolycarboxylate (APC) ligands, with organic metalchelating compounds goes beyond decreasing the environmental footprint of microalgal production practices to confer production advantages.

Microalgal species examined in this study are widely cultivated for live single-cell feed production during larval rearing of bivalves, crustaceans, and marine fish in aquaculture hatcheries (Borowitzka 1997). Observed increased specific growth rates of $C$. calcitrans cultures, paired with doubling of the final cell yield when grown in GLU-chelated growth media, are advantages maximizing microalgal production output (Oostlander et al. 2020). Additionally, enhanced biosynthesis of omega-3 PUFA in C. calcitrans in the presence of GLU is an important added-value, as PUFAs are an essential and short-supplied ingredient in aquacultural feeds (Tocher 2015).

Chaetoceros calcitrans has been found to be difficult to grow in continuous cultures systems, and thus is widely produced in labor-intensive batch culture systems ranging from carboys to plastic bags to high-volume tanks (Kaspar et al. 2014). Our proposed modifications of seawater enrichment represent a strategy to (i) reduce the time interval between inoculation and harvest, (ii) significantly increase cell yields of labor-intensive microalgal cultures, and (iii) improve the algal biomass biochemical profile by increasing omega-3 PUFA content at no additional cost relative to industry standard (EDTA). Proposed EDTA alternatives are readily applicable across commercial high-density microalgal production systems and are operationally equivalent (shelf life, thermal stability, etc.).

Microbially derived organic compounds and other EPS components (e.g., alginate, sulfated polysaccharides) possess a spectrum of physiochemical properties and bioactivities of relevance for pharmaceutical applications (e.g., antiviral, antibacterial, anti-inflammatory, antioxidant, and immunostimulatory activities), as well as biotechnological applications (anti-adhesive, biosurfactant, and bioemulsifying properties) (Xiao and Zheng 2016; Yu et al. 2018). Inclusion of these compounds in microalgal growth media formulations may also contribute to beneficial downstream effects for the marine animals consuming microalgal feeds, such as improved resistance to abiotic and biotic stressors. Microbial EPS, such as dextran (synthesized by Lactobacillus sakei MN1), have been confirmed to possess antiviral and immunomodulatory properties, for instance against salmonid viruses (NácherVázquez et al. 2015). Similarly, immunostimulatory effects in juvenile shellfish, white shrimp, and juvenile carp have been reported following dietary supplementation with marine (alginate-derived) oligosaccharides (Mohan et al. 2019). Hence, marine-derived saccharides and other EPS components, closely resembling the candidate metal chelators examined in this study, show notable promise to optimize microalgal cultivation practices but also the growth performance and health conditions of aquatic animals.

\section{Conclusion}

Replacement of EDTA as a metal-chelating agent in microalgal seawater enrichments with several candidate alternatives was shown to have significant advantages related to culture performance of relevance for industrial microalgal production. Perhaps more importantly, substituting biodegradable ligands for EDTA, which can be characterized as a persistent organic pollutant, answers the societal call for aquaculture and other industrial practices that are environmentally benign and sustainable.

$\mathrm{Fe}$ is fundamental for algal metabolism; therefore, sufficient Fe bioavailability for microalgal cultivation is an important consideration for the development of highoutput marine microalgal production systems. This study demonstrates that substitution of EDTA in the growth media by organic metal-chelating compounds characterized by a weak binding capacity for metallic cations (e.g., glucuronic acid, alginic acid, and dextran) has no detrimental effect, and can enhance growth and biochemical composition of two model marine microalgal species, Chaetoceros calcitrans and Tisochrysis lutea. Besides presenting an environmentally sustainable alternative to EDTA, modifications of media formulations to include organic metal-chelating compounds have the potential to increase specific growth rates, especially in the early stages of microalgae culture development, increase final cell yield, and increase the omega-3 PUFA content of algal biomass. The beneficial effects of organic chelators upon algal growth, yield, and nutritional composition are likely attributable to Fe uptake pathways, which depend upon the types and concentrations of chelating ligands, combined 
with the potential for mixotrophy of the microalgal species considered. Proposed organic metal-chelating enrichment alternatives are easily implementable in current microalgal cultivation practices, add no significant additional cost, and furthermore have the potential to enhance the productivity and nutritional profile of microalgae of relevance to a wide range of algae-based biotechnologies.

Acknowledgements We thank Mark Dixon and Heather Ferranti, at the NOAA Milford Laboratories, and Mark Gluis and Dr Yibing Liu, at the SARDI-PIRSA, for their insights and assistance during the experimental phase of this project. We thank Geert Van de Wiele and Ilse Daveloose at Ghent University, and Prof Jim Mitchell and Dr James Patterson, at Flinders University, and the Immunology Laboratory of the Flinders University Medical Center for their support with the execution of this project.

Funding Open access funding provided by University of Gothenburg. This work was supported by the Swedish Research Council (Joyce 2018- 05932), the Adlerbertska Foundation, the Längmanska Kulturfonden Foundation, and the Knut and Alice Wallenberg Foundation. The research leading to results presented in this publication was carried out with infrastructure funded by EMBRC Belgium-The Research Foundation-Flanders (FWO) international research infrastructure I001621N and FWO Hercules Medium-scale research infrastructure.

\section{Declarations}

Competing interests The authors declare no competing interests.

Open Access This article is licensed under a Creative Commons Attribution 4.0 International License, which permits use, sharing, adaptation, distribution and reproduction in any medium or format, as long as you give appropriate credit to the original author(s) and the source, provide a link to the Creative Commons licence, and indicate if changes were made. The images or other third party material in this article are included in the article's Creative Commons licence, unless indicated otherwise in a credit line to the material. If material is not included in the article's Creative Commons licence and your intended use is not permitted by statutory regulation or exceeds the permitted use, you will need to obtain permission directly from the copyright holder. To view a copy of this licence, visit http://creativecommons.org/licenses/by/4.0/.

\section{References}

Abd El Baky HH, El-Baroty GS, Bouaid A, Martinez M, Aracil J (2012) Enhancement of lipid accumulation in Scenedesmus obliquus by optimizing $\mathrm{CO}_{2}$ and $\mathrm{Fe}^{3+}$ levels for biodiesel production. Bioresour Technol 119:429-432

Alldredge AL, Passow U, Logan BE (1993) The abundance and significance of a class of large, transparent organic particles in the ocean. Deep Sea Res I 40:1131-1140

Aluwihare LI, Repeta DJ, Chen RF (1997) A major biopolymeric component to dissolved organic carbon in surface sea water. Nature 387:166-169

Anderson MA, Morel FM (1982) The influence of aqueous iron chemistry on the uptake of iron by the coastal diatom Thalassiosira weissflogii 1. Limnol Oceanogr 27:789-813

Bendif EM, Probert I, Schroeder DC, de Vargas C (2013) On the description of Tisochrysis lutea gen. nov. sp. nov. and
Isochrysis nuda sp. nov. in the Isochrysidales, and the transfer of Dicrateria to the Prymnesiales (Haptophyta). J Appl Phycol 25:1763-1776

Benner R (2011) Loose ligands and available iron in the ocean. Proc Natl Acad Sci 108:893-894

Bittar TB, Passow U, Hamaraty L, Bidle KD, Harvey EL (2018) An updated method for the calibration of transparent exopolymer particle measurements. Limnol Oceanogr: Meth 16:621-628

Borowitzka MA (1997) Microalgae for aquaculture: opportunities and constraints. J Appl Phycol 9:393-401

Brown M, Blackburn S (2013) Live microalgae as feeds in aquaculture hatcheries. In: Allan G, Burnell G (eds) Advances in aquaculture hatchery technology. Woodhead Publishing, Oxford, pp 117-158e

Bruland KW, Donat JR, Hutchins DA (1991) Interactive influences of bioactive trace metals on biological production in oceanic waters. Limnol Oceanogr 36:1555-1577

Burkholder JM, Glibert PM, Skelton HM (2008) Mixotrophy, a major mode of nutrition for harmful algal species in eutrophic waters. Harmful Algae 8:77-93

Byrne RH, Kester DR (1976) Solubility of hydrous ferric oxide and iron speciation in seawater. Mar Chem 4:255-274

Croot PL, Andersson K, Öztürk M, Turner DR (2004) The distribution and speciation of iron along $6 \mathrm{E}$ in the Southern Ocean. Deep Sea Res II 51:2857-2879

Cullen JT, Sherrell RM (1999) Techniques for determination of trace metals in small samples of size-fractionated particulate matter: phytoplankton metals off central California. Mar Chem 67:233-247

Decho AW, Gutierrez T (2017) Microbial extracellular polymeric substances (EPSs) in ocean systems. Front Microbiol 8:922

Enzing C, Ploeg M, Barbosa M, Sijtsma L, authors Vigani M, Parisi C, Rodriguez Cerezo E, editors (2014) Microalgae-based products for the food and feed sector: an outlook for Europe. EUR 26255. Publications Office of the European Union, Luxembourg. JRC85709 pp19-37

Flemming H-C, Wingender J (2001) Relevance of microbial extracellular polymeric substances (EPSs)-part I: structural and ecological aspects. Water Sci Technol 43:1-8

Gerringa L, De Baar H, Timmermans K (2000) A comparison of iron limitation of phytoplankton in natural oceanic waters and laboratory media conditioned with EDTA. Mar Chem 68:335-346

Gledhill M, Buck KN (2012) The organic complexation of iron in the marine environment: a review. Front Microbiol 3:69

Guedes AC, Malcata FX (2012) Nutritional value and uses of microalgae in aquaculture. Aquaculture 10:59-78

Guillard R (1973) Culture methods and growth measurements. In: Stein JR (ed) Handbook of phycological methods. Cambridge University Press, Cambridge, pp 289-312

Guillard RRL (1975) Culture of phytoplankton for feeding marine invertebrates. In: Smith WL, Chanley MH (eds) Culture of marine invertebrate animals. Plenum Press, New York, pp 29-60

Guillard RR, Ryther JH (1962) Studies of marine planktonic diatoms: I. Cyclotella nana Hustedt, and Detonula confervacea (Cleve) Gran. Can J Microbiol 8:229-239

Gutierrez T, Biller DV, Shimmield T, Green DH (2012) Metal binding properties of the EPS produced by Halomonas sp. TG39 and its potential in enhancing trace element bioavailability to eukaryotic phytoplankton. Biometals 25:1185-1194

Hasegawa H, Nozawa A, Papry RI, Maki T, Miki O, Rahman MA (2018) Effect of biodegradable chelating ligands on Fe uptake in and growth of marine microalgae. J Appl Phycol 30:2215-2225

Hasegawa H, Rahman MM, Kadohashi K, Takasugi Y, Tate Y, Maki T, Rahman MA (2012) Significance of the concentration of chelating ligands on $\mathrm{Fe}^{3+}$-solubility, bioavailability, and uptake in rice plant. Plant Physiol Biochem 58:205-211 
Hassler C, Schoemann V (2009) Bioavailability of organically bound Fe to model phytoplankton of the Southern Ocean. Biogeosciences 6:2281-2296

Hassler CS, Norman L, Nichols CAM, Clementson LA, Robinson C, Schoemann V, Watson RJ, Doblin MA (2015) Iron associated with exopolymeric substances is highly bioavailable to oceanic phytoplankton. Mar Chem 173:136-147

Hassler CS, Schoemann V, Nichols CM, Butler EC, Boyd PW (2011) Saccharides enhance iron bioavailability to Southern Ocean phytoplankton. Proc Natl Acad Sci 108:1076-1081

Hassler CS, van den Berg CM, Boyd PW (2017) Toward a regional classification to provide a more inclusive examination of the ocean biogeochemistry of iron-binding ligands. Front Mar Sci 4:19

Helm M (2004) Hatchery culture of bivalves. Food and Agriculture Organization of the United Nations, Rome

Hoagland KD, Rosowski JR, Gretz MR, Roemer SC (1993) Diatom extracellular polymeric substances: function, fine structure, chemistry, and physiology. J Phycol 29:537-566

Hunter KA, Boyd PW (2007) Iron-binding ligands and their role in the ocean biogeochemistry of iron. Environ Chem 4:221-232

Hutner SH, Provasoli L, Schatz A, Haskins C (1950) Some approaches to the study of the role of metals in the metabolism of microorganisms. Proc Am Phil Soc 94:152-170

Johnson KS, Gordon RM, Coale KH (1997) What controls dissolved iron concentrations in the world ocean? Mar Chem 57:137-161

Joyce A, Utting S (2015) The role of exopolymers in hatcheries: an overlooked factor in hatchery hygiene and feed quality. Aquaculture 446:122-131

Kaspar HF, Keys EF, King N, Smith KF, Kesarcodi-Watson A, Miller MR (2014) Continuous production of Chaetoceros calcitrans in a system suitable for commercial hatcheries. Aquaculture 420:1-9

Kennedy A, Sutherland I (1987) Analysis of bacterial exopolysaccharides. Biotechnol Appl Biochem 9:12-19

Khan MI, Shin JH, Kim JD (2018) The promising future of microalgae: current status, challenges, and optimization of a sustainable and renewable industry for biofuels, feed, and other products. Microb Cell Fact 17:1-21

Koller M, Muhr A, Braunegg G (2014) Microalgae as versatile cellular factories for valued products. Algal Res 6:52-63

Lavens P, Sorgeloos P (1996) Manual on the production and use of live food for aquaculture. vol 361. Food and Agriculture Organization (FAO), Rome

Lepage G, Roy CC (1984) Improved recovery of fatty acid through direct transesterification without prior extraction or purification. J Lipid Res 25:1391-1396

Li Y, Veilleux DJ, Wikfors GH (2009) Particle removal by Northern bay scallops Argopecten irradians irradians in a semi-natural setting: application of a flow-cytometric technique. Aquaculture 296:237-245

Liu H, Fang HH (2002) Characterization of electrostatic binding sites of extracellular polymers by linear programming analysis of titration data. Biotechnol Bioeng 80:806-811

Liu Z-Y, Wang G-C, Zhou B-C (2008) Effect of iron on growth and lipid accumulation in Chlorella vulgaris. Bioresour Technol 99:4717-4722

Maldonado MT, Strzepek RF, Sander S, Boyd PW (2005) Acquisition of iron bound to strong organic complexes, with different Fe binding groups and photochemical reactivities, by plankton communities in Fe-limited subantarctic waters. Glob Biogeochem Cycles 19(4)

Marchetti A, Maldonado M (2016) Iron. In: Borowitzka MA, Beardall J, Raven JA (eds) The physiology of microalgae. Springer, Cham, pp 233-279

Marchetti A, Maldonado MT, Lane ES, Harrison PJ (2006) Iron requirements of the pennate diatom Pseudo-nitzschia: comparison of oceanic (high-nitrate, low-chlorophyll waters) and coastal species. Limnol Oceanogr 51:2092-2101

Milne A, Landing W, Bizimis M, Morton P (2010) Determination of $\mathrm{Mn}, \mathrm{Fe} \mathrm{Co}, \mathrm{Ni}, \mathrm{Cu}, \mathrm{Zn}, \mathrm{Cd}$ and $\mathrm{Pb}$ in seawater using high resolution magnetic sector inductively coupled mass spectrometry (HR-ICP-MS). Anal Chim Acta 665:200-207

Mohan K, Ravichandran S, Muralisankar T, Uthayakumar V, Chandirasekar R, Seedevi P, Abirami RG, Rajan DK (2019) Application of marine-derived polysaccharides as immunostimulants in aquaculture: a review of current knowledge and further perspectives. Fish Shellfish Immunol 86:1177-1193

Morel FM, Kustka A, Shaked Y (2008) The role of unchelated $\mathrm{Fe}$ in the iron nutrition of phytoplankton. Limnol Oceanogr 53(1):400-404

Muller-Feuga A (2013) Microalgae for aquaculture: the current global situation and future trends. In: Richmond A, Hu Q (eds) Handbook of microalgal cultures: applied phycology and biotechnology, 2nd edn. Wiley Blackwell, West Sussex, pp 615-627

Myers J, Phillips JN Jr, Graham J-R (1951) On the mass culture of algae. Plant Physiol 26:539

Nácher-Vázquez M, Ballesteros N, Canales Á, Saint-Jean SR, PérezPrieto SI, Prieto A, Aznar R, López P (2015) Dextrans produced by lactic acid bacteria exhibit antiviral and immunomodulatory activity against salmonid viruses. Carbohydr Polym 124:292-301

Nichols CM, Lardière SG, Bowman JP, Nichols PD, Gibson JA, Guézennec J (2005) Chemical characterization of exopolysaccharides from Antarctic marine bacteria. Microb Ecol 49:578-589

Nicolas J-L, Corre S, Cochard J-C (2004) Bacterial population association with phytoplankton cultured in a bivalve hatchery. Microb Ecol 48:400-413

Norman L, Worms IA, Angles E, Bowie AR, Nichols CM, Pham AN, Slaveykova VI, Townsend AT, Waite TD, Hassler CS (2015) The role of bacterial and algal exopolymeric substances in iron chemistry. Mar Chem 173:148-161

Oostlander P, van Houcke J, Wijffels R, Barbosa M (2020) Microalgae production cost in aquaculture hatcheries. Aquaculture $525: 735310$

Oviedo C, Rodríguez J (2003) EDTA: the chelating agent under environmental scrutiny. Quim Nova 26:901-905

Passow U, Alldredge A (1995) A dye-binding assay for the spectrophotometric measurement of transparent exopolymer particles (TEP). Limnol Oceanogr 40:1326-1335

Pinto IS, Neto IF, Soares HM (2014) Biodegradable chelating agents for industrial, domestic, and agricultural applications - a review. Environ Sci Pollut Res 21:11893-11906

Rahman MA, Hasegawa H, Kadohashi K, Maki T, Ueda K (2009) Hydroxyiminodisuccinic acid (HIDS): a novel biodegradable chelating ligand for the increase of iron bioavailability and arsenic phytoextraction. Chemosphere 77:207-213

Richmond A (ed) (2008) Handbook of microalgal culture: biotechnology and applied phycology. John Wiley \& Sons, NY

Rue E, Bruland K (2001) Domoic acid binds iron and copper: a possible role for the toxin produced by the marine diatom Pseudonitzschia. Mar Chem 76:127-134

Rue EL, Bruland KW (1995) Complexation of iron (III) by natural organic ligands in the Central North Pacific as determined by a new competitive ligand equilibration/adsorptive cathodic stripping voltammetric method. Mar Chem 50:117-138

Rue EL, Bruland KW (1997) The role of organic complexation on ambient iron chemistry in the equatorial Pacific Ocean and the response of a mesoscale iron addition experiment. Limnol Oceanogr 42:901-910

Sauvage J, Wikfors GH, Li X, Gluis M, Nevejan N, Sabbe K, Joyce A (2021) Effect of pluronic block polymers and N-acetylcysteine 
culture media additives on growth rate and fatty acid composition of six marine microalgae species. Appl Microbiol Biotechnol 105:2139-2156

Shaked Y, Kustka AB, Morel FM (2005) A general kinetic model for iron acquisition by eukaryotic phytoplankton. Limnol Oceanogr 50:872-882

Shaked Y, Lis H (2012) Disassembling iron availability to phytoplankton. Front Microbiol 3:123

Singh P, Guldhe A, Kumari S, Rawat I, Bux F (2015) Investigation of combined effect of nitrogen, phosphorus and iron on lipid productivity of microalgae Ankistrodesmus falcatus KJ671624 using response surface methodology. Biochem Eng J 94:22-29

Smith JP, Hughes A, McEvoy L, Day J (2020) Tailoring of the biochemical profiles of microalgae by employing mixotrophic cultivation. Bioresour Technol Rep 9:100321

Sun X, Cao Y, Xu H, Liu Y, Sun J, Qiao D, Cao Y (2014) Effect of nitrogen-starvation, light intensity and iron on triacylglyceride/ carbohydrate production and fatty acid profile of Neochloris oleoabundans HK-129 by a two-stage process. Bioresour Technol 155:204-212

Sunda WG, Huntsman SA (1995a) Cobalt and zinc interreplacement in marine phytoplankton: biological and geochemical implications. Limnol Oceanogr 40:1404-1417

Sunda WG, Huntsman SA (1995b) Iron uptake and growth limitation in oceanic and coastal phytoplankton. Mar Chem 50:189-206

Sunda WG, Price NM, Morel FM (2005) Trace metal ion buffers and their use in culture studies. In: Andersen R (ed) Algal culturing techniques. Academic Press, Burlington, pp 35-63

Tocher DR (2015) Omega-3 long-chain polyunsaturated fatty acids and aquaculture in perspective. Aquaculture 449:94-107
Tredici M, Biondi N, Ponis E, Rodolfi L, Zittelli GC (2009) Advances in microalgal culture for aquaculture feed and other uses. In: Burnell G, Allan G (eds) New technologies in aquaculture. CRC Press, Boca Raton, pp 610-676

Tsitsa-Tzardis E, Patterson G, Wikfors G, Gladu P, Harrison D (1993) Sterols of Chaetoceros and Skeletonema. Lipids 28:465-467

Turner DR, Hunter KA (2001) The biogeochemistry of iron in seawater, vol 6. Wiley Chichester, London

Vanthoor-Koopmans M, Wijffels RH, Barbosa MJ, Eppink MH (2013) Biorefinery of microalgae for food and fuel. Bioresour Technol 135:142-149

Völker C, Wolf-Gladrow DA (1999) Physical limits on iron uptake mediated by siderophores or surface reductases. Mar Chem 65:227-244

Worms I, Simon DF, Hassler C, Wilkinson K (2006) Bioavailability of trace metals to aquatic microorganisms: importance of chemical, biological and physical processes on biouptake. Biochimie 88:1721-1731

Xiao R, Zheng Y (2016) Overview of microalgal extracellular polymeric substances (EPS) and their applications. Biotechnol Adv 34:1225-1244

Yarnold J, Karan H, Oey M, Hankamer B (2019) Microalgal aquafeeds as part of a circular bioeconomy. Trends Plant Sci 24:959-970

Yu Y, Shen M, Song Q, Xie J (2018) Biological activities and pharmaceutical applications of polysaccharide from natural resources: a review. Carbohydr Polym 183:91-101

Publisher's note Springer Nature remains neutral with regard to jurisdictional claims in published maps and institutional affiliations. 